\title{
Orchestrated response: a symphony of transcription factors for gene control
}

\author{
Bryan Lemon $^{1}$ and Robert Tjian ${ }^{1,2,3}$ \\ ${ }^{1}$ Department of Molecular and Cell Biology and ${ }^{2}$ Howard Hughes Medical Institute, University of California Berkeley, \\ Berkeley, California 94720, USA
}

An enormous body of work generated over the past three decades has revealed that eukaryotic gene transcription is a remarkably intricate biochemical process that is tightly regulated at many levels. Biochemical and genetic analysis of various model organisms has identified an astounding number of protein factors responsible for transcriptional control. Although a large assortment of gene-specific DNA-binding regulators was somewhat anticipated, the sheer complexity of the general machinery relative to prokaryotes has been a surprise. Even more unexpected were the numerous and intricate layers of control imposed by the diversification of co-activators and co-repressors, some of which possess enzymatic activities. Many interactions between the identified factors and some of their rate-limiting steps have been discerned. Despite these advances, surprisingly little is known about the detailed mechanisms by which individual genes are turned on or off in a cell. Recent evidence suggests that there is an ordered progression of events leading to RNA synthesis in vivo and that a highly structured eukaryotic nucleus may be important in orchestrating transcription. In this review, we present our interpretation of recent findings and discuss various models that integrate these observations with the emerging elaborate molecular apparatus that has evolved to control gene expression.

Eukaryotic cells carry a tremendous amount of genetic information just to encode the 6000 to 100,000 proteins necessary to perpetuate life from yeast to animals. In addition, genomes must also contain vast amounts of cis-regulatory DNA responsible for directing spatial and temporal patterns of gene expression in response to metabolic requirements, developmental programs, and a plethora of external stimuli. To maintain and control such a large genetic load, eukaryotes have organized colinear DNA into discrete chromosomes each packaged into chromatin, the minimal unit of which has been defined as the nucleosome (Kornberg 1974; Luger et al. 1997). Variable degrees of DNA sequence accessibility exist within chromatin throughout the cell cycle to ac-

${ }^{3}$ Corresponding author.

E-MAIL jmlim@uclink4.berkeley.edu; FAX (510) 643-9547.

Article and publication are at www.genesdev.org/cgi/doi/10.1101/ gad.831000. commodate essential biological processes such as DNA replication, gene expression, and cell division. However, classically held notions of chromatin as merely a passive DNA-packaging vehicle and global repressor of transcription have proven to be inadequate to explain its role in gene expression (Lorch et al. 1987; for review, see Grunstein 1992). Instead, it has become clear that chromatin is a dynamic and active participant in regulating transcription of the eukaryotic genome. Thus, the question of how gene expression is regulated in complex eukaryotic genomes has re-focused on the molecular machines that have evolved to navigate through chromatin and mediate transcriptional control.

\section{Diversification of transcription factors}

Aside from the unique physical properties imparted by chromatin to the DNA template, the first indication that mechanisms of eukaryotic transcription might have diverged significantly from prokaryotes was suggested decades ago by the finding that animal cells employ three distinct and separate enzymes for RNA synthesis (Roeder and Rutter 1969). Fine structure mapping and genetic analysis of a few highly expressed cellular genes and other transcription units harbored by DNA tumor viruses that utilize the host cell machinery led to the discovery of cis control elements responsible for directing the transcription of protein-encoding genes by RNA polymerase II (Pol II; Fig. 1A; for review, see McKnight and Tjian 1986; Maniatis et al. 1987). It was soon appreciated that eukaryotic genes contain complex arrays of specific DNA sequences that combine more commonly shared core promoter elements with broadly diverse gene-specific enhancer elements and cooperate to define specific expression patterns (for review, see Dynan 1989). Because prokaryotic core RNA polymerases require additional subunits, called $\sigma$ factors, for DNA recognition (Bautz and Bautz 1970; for review, see McClure 1985), it was not surprising to find that animal RNA polymerases require a cadre of accessory factors to recognize promoters and accurately initiate transcription (Matsui et al. 1980; Samuels et al. 1982). Despite these early hints of diversification from prokaryotic mechanisms, the enormous complexity of the eukaryotic transcription machinery was unanticipated. Instead, it was hypothesized 

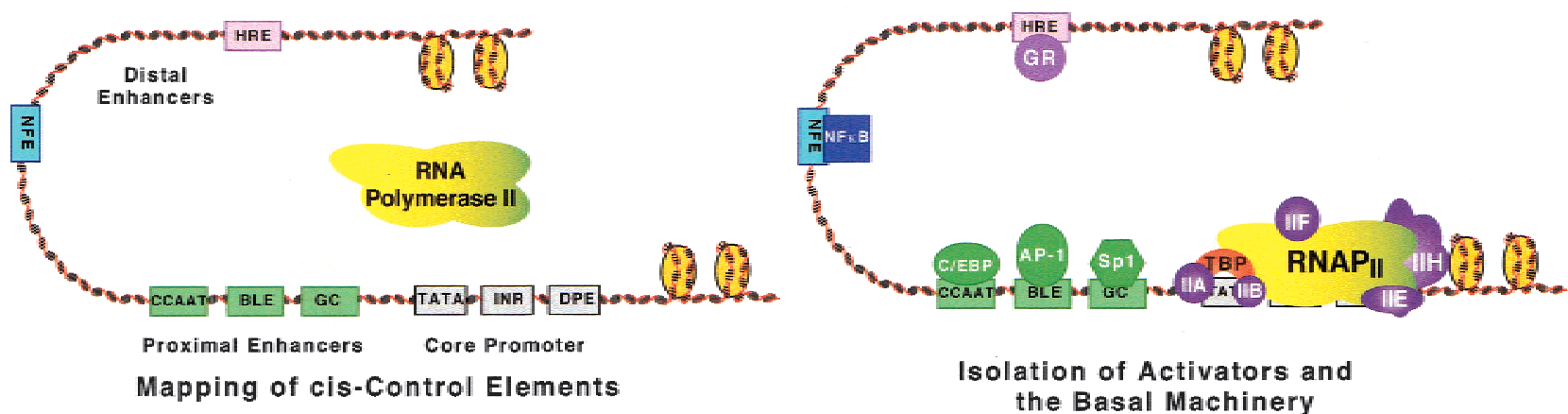

Isolation of Activators and the Basal Machinery

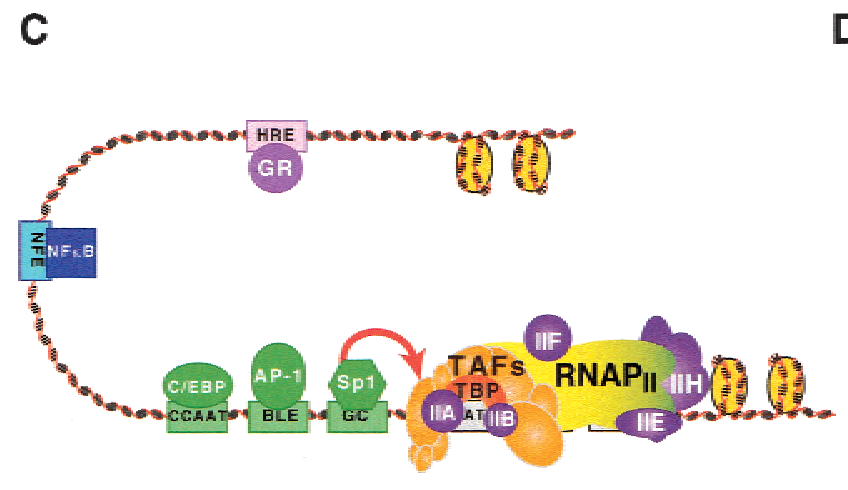

Discovery of Co-Activators

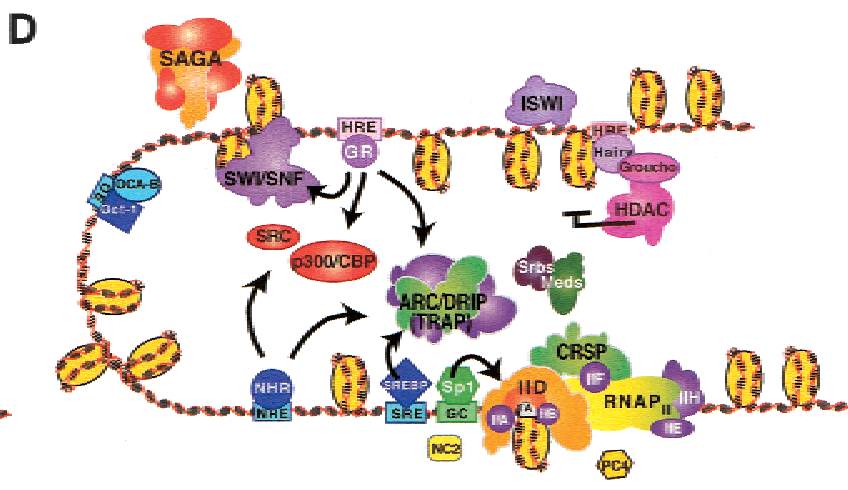

Diversity of Co-Regulators

Figure 1. Fundamental elements of eukaryotic transcriptional control. (A) Early studies led to the identification of multiple eukaryotic RNA polymerases and the mapping of promoter and enhancer DNA sequences. Core promoter elements (grey) that direct transcription by RNA Pol II (yellow, green shading) include the TATA box (TATA), the initiator (INR), and the downstream promoter element (DPE). Promoter-proximal basal level enhancer elements (BLE, GC box, CCAAT box, green) were found in many genes; however, gene-specific signal-responsive distal enhancer elements were also identified and are represented here as the hormone responsive element (HRE, purple) and nuclear factor element (NFE, blue). (B) Sequence-specific DNA-binding transcription factors that were isolated biochemically include specificity protein-1 (Sp1, green), families of activator proteins (i.e., AP-1, green), CCAAT enhancer-binding proteins (C/EBP), steroid receptors (i.e., glucocorticoid or GR, purple) and tissue-specific transcription factors (i.e., NF- $\mathrm{B}$, blue). Components of the core initiation machinery required by RNA Pol II for promoter recognition and basal transcription from naked DNA were also fractionated biochemically, including TATA-binding protein, (TBP, red) and general transcription factors (TFIIA, TFIIB, TFIID, TFIIE, TFIIF and TFIIH, purple). (C) Because TBP is insufficient for activated transcription, discovery of TAF subunits (orange) within TFIID revealed a requirement for co-activators to mediate activator responsiveness. Depicted here is one example of a specific and functional interaction between Sp1 and Drosophila TAF110 (human TAF130). (D) Many co-activators and co-repressors were subsequently found to be required for mediating signals between sequence-specific transcription factors and the core machinery. For further discussion pertaining to the specific co-regulators depicted, see text and Table 1.

that enhancer-bound activators would directly recruit RNA polymerase to promoters in nucleosome-free regions of the DNA template to initiate RNA synthesis (for review, see Ptashne 1988; Mitchell and Tjian 1989; Ptashne and Gann 1997). It is now clear that this simplistic view is no longer tenable and falls far short of the elegant, and elaborate, mechanisms that have evolved to regulate eukaryotic transcription.

The molecular underpinnings of the eukaryotic transcriptional apparatus have largely been dissected and reconstructed over the past two decades. Combined with genetic approaches in yeast and Drosophila, purification of transcription factors from mammalian cells with sensitive biochemical assays during the first 10 years (1980-1990) revealed the existence of large families of sequence-specific activators (Fig. 1B; i.e., Sp1, AP$1, \mathrm{C} / \mathrm{EBP}, \mathrm{NF}-\kappa \mathrm{B}, \mathrm{GR}$, etc.) as well as a host of accessory factors (Fig. 1B; i.e., TFIIA, TFIIB, TFIID, TFIIE, TFIIF and TFIIH) necessary to program a functional RNA Pol II complex (Dynan and Tjian 1983; for review, see McKnight and Tjian 1986; Guarente 1987; Levine and Hoey 1988; Mitchell and Tjian 1989; Conaway and Conaway 1993). The availability of robust in vitro transcription reactions uncovered multiple biochemical steps and helped to establish a general order of assembly of these factors for the formation of active pre-initiation com- 
plexes in vitro (Buratowski et al. 1989). The development of DNA affinity chromatography methods and various molecular cloning strategies for isolating transcription factors enabled investigators to identify many sequencespecific enhancer-binding proteins (Weinberger et al. 1985; Miesfeld et al. 1986; Johnson et al. 1987; Kadonaga et al. 1987) and, subsequently, to further refine the multi-subunit nature of the transcription machinery (Fig. 1B).

These studies, in turn, enabled the biochemical characterization of the first cloned eukaryotic general accessory factor, TFIID, which at the time was thought to be equivalent to the single polypeptide identified as the TATA-binding protein, TBP (Hahn et al. 1989; Horikoshi et al. 1989). However, it was soon learned that, although recombinant TBP could replace a crude TFIID fraction to initiate basal transcription, TBP could not support activated transcription in response to enhancer-binding regulators (Pugh and Tjian 1990). It was subsequently determined that purified TFIID is, in fact, a multi-subunit complex containing TBP and several tightly associated factors or TAFs (Dynlacht et al. 1991; Tanese et al. 1991). Importantly, although critical for mediating activator responsiveness, the TAF subunits of TFIID are dispensable for basal transcription (Figs. 1B,C). These experiments led to the co-activator hypothesis which posited that a new class of molecules, called co-activators or adapters, were necessary to relay information imparted by the DNA-bound activators to the RNA Pol II machinery (Pugh and Tjian 1990). In the decade since (1990 to the present), biochemical and genetic analysis from yeast to man has helped to identify most of the components of the general initiation machinery as well as a continually expanding array of co-activators and co-repressors (Fig. 1D; for review, see Goodrich et al. 1996; Orphanides et al. 1996; Kingston and Narlikar 1999; Maldonado et al. 1999; Tyler and Kadonaga 1999; Brown et al. 2000; Glass and Rosenfeld 2000). These later studies have not only uncovered the amazingly elaborate nature of the eukaryotic transcription machinery but have also firmly established the importance of co-activators in mediating transcriptional control.

\section{A requirement for co-regulators}

A defining characteristic that discriminates between different genes in a genome is the unique bank of cis-regulatory sites recognized by sequence-specific DNA-binding factors. In principle, these regulators should be able to directly instruct the transcription apparatus to initiate RNA synthesis at a specific core promoter. This view was strongly supported by findings in prokaryotes in which sequence-specific regulators, such as the phage $\lambda$ cI protein, recruit RNA polymerase to the promoter through direct contact with the $\sigma$-subunit of the enzyme (Hochschild et al. 1983; for review, see McClure 1985). Considering the mechanisms of transcriptional regulators in prokaryotes, how do we rationalize the need for the diversity of co-regulators that have evolved in eukaryotes, most dramatically in metazoans? Given that animal cells likely utilize from 1000 to 10,000 different transcriptional regulators, it is not difficult to imagine the need for specialized adapters employed by different classes of activators and repressors to interface with a limited number of targets within the general transcription apparatus. Although some of these regulators may have similar types of activation or repression domains, upon inspection of their primary sequences, context-dependent structural effects imposed on these domains very likely contribute higher orders of complexity. For example, allosteric controls on interactions of regulators with their targets can be exerted through subtle differences in DNA binding sites as well as through interactions between clustered trans-acting factors in specific DNA-localized complexes, sometimes referred to as enhanceosomes (Diamond et al. 1990; for review, see Carey 1998; Lefstin and Yamamoto 1998). Considering the potential for a vast diversity of molecular signals that must be interpreted by the transcriptional apparatus, it would appear to be untenable for each gene-selective regulator to have a designated and unique target within the limited repertoire of the general machinery. Instead, it is now evident that a given regulator can partner and function with multiple types of co-activators or co-repressors and vice versa (Fig. 1D; Onate et al. 1995; Fondell et al. 1996; Kamei et al. 1996; Mengus et al. 1997; Nagy et al. 1997).

Most genes are regulated by mixing and matching different types of activators and repressors in a coordinated fashion. Consistent with the notion of combinatorial specificity in regulator-co-regulator interactions, many transcriptional co-factors are constituents of multi-subunit complexes, such as TFIID. Studies of the TFIID complex, including an extensive biochemical analysis of TAF-activator and TAF-basal factor interactions, revealed that different classes of activators can target distinct TAFs to effect transcription (Goodrich et al. 1993; Chen et al. 1994; for review, see Burley and Roeder 1996). While many sequence-specific DNA-binding regulators exhibit cell-type-specific expression patterns (Lenardo and Baltimore 1989; for review, see Lai and Darnell 1991), it has become increasingly evident that some transcriptional co-regulators may also have tissue-restricted expression. For example, some TFIID subunits apparently function in a tissue-specific manner as exemplified by human TAF105, the first identified cell-type-restricted TAF, which is highly expressed in B cells (Dikstein et al. 1996b). Moreover, at least two genes expressing testes-specific TAFs, cannonball and no-hitter, have been identified in Drosophila (M.T. Fuller, pers. comm.). There will likely be other tissue-restricted TAF subunits resulting in the assembly of different TFIID complexes in vivo, which would increase permutations of regulator-co-regulator interactions and may play a role in regulating cell-type-specific gene expression. Extending these properties to other co-regulators, the requirement for transcriptional co-factors to interface with diverse enhancer and promoter factors could, therefore, be efficiently accommodated by a limited number of multisubunit co-regulator complexes, which themselves might 
be alternately assembled. Together with differential expression patterns, additional controls resulting from modification of regulators or co-regulators via cellular signal transduction pathways could allow the vast numbers of trans-acting factors to target different subsets of requisite co-regulators at different genes or in different cell types.

\section{Classifying a profusion of co-activators and co-repressors}

It is evident that studying the mechanisms by which co-activators and co-repressors interface with gene regulators and the transcription machinery has become essential to understanding transcriptional regulation in eukaryotes. Broadly defined, transcriptional co-factors could be divided into five classes (Table 1 and below). The first class includes those co-factors that are intrinsic to or intimately associated with components of the core machinery. For example, the TAFs of the TFIID complex would fit into Class I along with other general co-regulators such as TFIIA, and, possibly, PC4 and NC2 (Dynlacht et al. 1991; Tanese et al. 1991; Ge and Roeder 1994; Yokomori et al. 1994; Mermelstein et al. 1996). A second class of co-factors includes those that are principally associated with activator or repressor molecules. Examples of Class II co-factors that bind sequence-specific factors and modulate DNA occupancy or interface with the core machinery include the cellular factors OCA-B (OBF-1/ Bob-1), Groucho, Notch, CtBP, and HCF along with viral co-regulators E1A and VP16 (Wilson et al. 1993; Strubin et al. 1995). A third class of co-factors is represented by a family of large multi-subunit co-activators that strictly fits into neither the general transcription factor-associated nor the activator-associated classes. Class III co-factors include the yeast Mediator (Thompson et al. 1993; Kim et al. 1994) and its recently identified albeit distantly related metazoan counterparts: (1) CRSP and PC2 (Ryu et al. 1999; Malik et al. 2000); (2) ARC/DRIP/TRAP (Ito et al. 1999; Näär et al. 1999; Rachez et al. 1999); and (3) NAT/SMCC/Srb-Mediator (Sun et al. 1998; Boyer et al. 1999; Gu et al. 1999). The remaining two classes include those co-factors that perform chromatin remodeling functions involved in antagonizing or enhancing the repressive effects of chromatin. Class IV co-factors include those that covalently modify nucleosomes. Members of this class are represented here by the histone acetylases CBP/p300, GCN5, P/CAF, and the SRC-1-related p160 family (Ogryzko et al. 1996; Yang et al. 1996; Grant et al. 1997; Spencer et al. 1997), as well as the histone deacetylases HDAC-1 and HDAC-2 $(\operatorname{rpd} 3)$, and

Table 1. A minimal classification of transcriptional co-regulators

\begin{tabular}{|c|c|c|c|}
\hline Class & General properties & Examples & References \\
\hline I & $\begin{array}{l}\text { activator and repressor targets inherent to the core } \\
\text { machinery, promoter recognition, and enzymatic } \\
\text { functions }\end{array}$ & TAFs, TFIIA, NC2, PC4 & a \\
\hline II & $\begin{array}{l}\text { activator and repressor adapters, modulate DNA } \\
\text { binding, target other co-regulators and the core } \\
\text { machinery }\end{array}$ & $\begin{array}{l}\text { OCA-B/OBF-1, Groucho, Notch, } \\
\text { CtBP, HCF, E1A, VP16 }\end{array}$ & $\mathrm{b}$ \\
\hline III & $\begin{array}{l}\text { multifunctional structurally related but highly } \\
\text { divergent co-regulators: some interact with RNA } \\
\text { Pol II and/or multiple types of activators, some } \\
\text { also appear to have inherent enzymatic } \\
\text { functions or chromatin-selective properties }\end{array}$ & $\begin{array}{l}\text { yeast: Mediator, SRBs } \\
\text { human a: CRSP, PC2 } \\
\text { human b: ARC/DRIP/TRAP } \\
\text { human c: NAT, SMCC, Srb/Mediator }\end{array}$ & $\mathrm{c}$ \\
\hline IV & $\begin{array}{l}\text { chromatin-modifying activator and repressor } \\
\text { adapters, acetyltransferase or deacetylase } \\
\text { activities with multiple substrates: histones, } \\
\text { histone-related proteins, activators, other } \\
\text { co-regulators and the core machinery }\end{array}$ & $\begin{array}{l}\mathrm{CBP} / \mathrm{p} 300, \mathrm{GCN} 5, \mathrm{P} / \mathrm{CAF}, \mathrm{p} 160 \mathrm{~s} \\
\text { (SRC1, TIF2, p/CIP, etc.), HDAC-1 } \\
\text { and HDAC-2 (rpd3), Sir2 }\end{array}$ & $\mathrm{d}$ \\
\hline $\mathrm{V}$ & ATP-dependent chromatin remodeling activities & $\begin{array}{l}\text { SNF2-ATPase (SWI/SNF, RSC) and } \\
\text { ISWI-ATPase (NURF, ACF, ChrAC, } \\
\text { RSF, etc.) }\end{array}$ & e \\
\hline
\end{tabular}

$\overline{{ }^{a}(H o e y ~ e t ~ a l . ~ 1993 ; ~ C h e n ~ e t ~ a l . ~ 1994 ; ~ G e ~ a n d ~ R o e d e r ~ 1994 ; ~ S u n ~ e t ~ a l . ~ 1994 ; ~ Y o k o m o r i ~ e t ~ a l . ~ 1994 ; ~ C h i ~ e t ~ a l . ~ 1995 ; ~ H a n s e n ~ a n d ~ T j i a n ~ 1995 ; ~}$ Verrijzer et al. 1995; Dikstein et al. 1996a; Mermelstein et al. 1996; Mizzen et al. 1996; Brandsen et al. 1997; Ikeda et al. 1998; Malik et al. 1998).

b(Triezenberg et al. 1988; Liu and Green 1990; Wilson et al. 1993; Jarriault et al. 1995; Luo and Roeder 1995; Strubin et al. 1995; Jimenez et al. 1997; Nibu et al. 1998; Chen et al. 1999).

'c(Thompson et al. 1993; Kim et al. 1994; Fondell et al. 1996; Holstege et al. 1998; Myers et al. 1998; Sun et al. 1998; Boyer et al. 1999; Gu et al. 1999; Ito et al. 1999; Näär et al. 1999; Ranchez et al. 1999; Ryu et al. 1999; Malik et al. 2000).

d(Kwok et al. 1994; Lundblad et al. 1995; Onate et al. 1995; Brownell et al. 1996; Ogryzko et al. 1996; Taunton et al. 1996; Voegel et al. 1996; Yang et al. 1996; Grant et al. 1997; Kadosh and Struhl 1997; Laherty et al. 1997; Nagy et al. 1997; Torchia et al. 1997; Utley et al. 1998; Xue et al. 1998; Zhang et al. 1998; Hamamori et al. 1999; Imai et al. 2000).

e(Laurent et al. 1991; Peterson and Herskowitz 1992; Tamkun et al. 1992; Yoshinaga et al. 1992; Imbalzano et al. 1994; Tsukiyama et al. 1995; Wang et al. 1996; LeRoy et al. 1998; Lorch et al. 1998; Schnitzler et al. 1998; Dimova et al. 1999; Hamiche et al. 1999; Ito et al. 1999; Kowenz-Leutz and Leutz 1999; Längst et al. 1999; Tsukiyama et al. 1999; Yudkovsky et al. 1999). 
Sir2 (Taunton et al. 1996; Kadosh and Struhl 1997; Zhang et al. 1997; Imai et al. 2000), each in combination with their respective associated polypeptides. Of note, Sir2 is an NAD-dependent deacetylase that additionally employs ADP-ribosylation in some of its enzymatic functions (Imai et al. 2000). Class V co-factors include those that hydrolyze ATP in catalytic reactions that perturb or reorganize chromatin structure represented by the SWI/ SNF-related and ISWI-containing chromatin remodeling complexes (Côté et al. 1994; Imbalzano et al. 1994; Tsukiyama et al. 1995).

It is noteworthy that, unlike components of the basal transcription machinery, the co-regulators have diverged both in structure and numbers when comparing metazoans with single-celled eukaryotes. Thus, it appears that we have unveiled the molecular machinery that could operate at a more species-specific or evolutionarily specialized level. The yeast Mediator was originally defined as a protein complex tightly associated with RNA Pol II via its carboxy-terminal repeat domain (CTD). As noted above, humans appear to have adopted a set of at least three structurally related Mediator-like complexes. While some of these complexes were observed to associate with RNA Pol II in vitro, these interactions apparently do not occur directly with the CTD (Sun et al. 1998; Gu et al. 1999; Näär et al. 1999). In addition, like the TAFs within TFIID, various subunits of some of these human complexes have been observed to bind selectively to specific activators (Boyer et al. 1999; Gu et al. 1999; Hittelman et al. 1999; Rachez et al. 1999). TAF subunits themselves were identified as intrinsic components of other multi-subunit co-regulators including the SAGA complex in yeast and other diverse GCN5- and P/CAF-containing complexes in metazoans (Grant et al. 1998; Martinez et al. 1998; Ogryzko et al. 1998; Wieczorek et al. 1998).

In addition to expanding the repertoire of commonly shared eukaryotic co-factors, it could be expected that metazoans have evolved additional levels of complexity for regulated transcription and may have acquired a need for other co-activator functions. The metazoan-specific acetyltransferases p300 and CBP have been observed to associate with several co-regulators, including the metazoan-specific p160 family of acetyltransferases, in seemingly distinct complexes (Kamei et al. 1996; Chen et al. 1997; Nakajima et al. 1997; Cho et al. 1998; McKenna et al. 1998). Are the observed co-factor complexes merely sub-complexes of a larger master co-regulator or could structurally and functionally distinct assemblages with multiple alternative subunits provide greater diversity and combinatorial specificity? This question brings us back to the larger issue of how the transcriptional machinery may be assembled and targeted to specific promoters.

\section{Two models at opposite ends of the spectrum}

\section{A stepwise assembly model}

An ordered assembly of the transcription pre-initiation complex was originally proposed on the basis of the for- mation of active transcription complexes in vitro (for review, see Buratowski 1994). It was observed that a stepwise addition of purified basal factors was required for promoter binding and transcription initiation from naked DNA templates (Fig. 2 and below). Steps leading to Pol II transcription defined biochemically include: (1) a metastable complex formed between TFIID, TFIIA, and TFIIB (DAB) capable of recognizing and binding to the TATA promoter element; (2) a more stable closed complex containing DAB, hypophoshorylated RNA Pol II and TFIIF; (3) an activated open complex formed by the further addition of TFIIE and TFIIH, which stimulate an ATP-dependent isomerization and promoter-melting event; and (4) promoter clearance and nascent RNA synthesis upon hyperphosphorylation of the RNA Pol II CTD (Buratowski et al. 1989; Wang et al. 1992; Tirode et al. 1999; for review, see Orphanides et al. 1996). Various biochemical steps during elongation of RNA synthesis have similarly been identified along with specific requirements for the accessory factors and enzymatic activities associated with transcription-coupled RNA processing such as $5^{\prime}$-capping, splicing, cleavage, and $3^{\prime}$ polyadenylation (for review, see Colgan and Manley 1997; McCracken et al. 1998; Bentley 1999; Tacke and Manley 1999).

Direct or indirect interaction of activators with constituents of the general machinery have long been observed to affect rates of complex formation and transcription (Fig. 2B; Horikoshi et al. 1988; Lin and Green 1991; Chi et al. 1995). A stepwise model for assembly of the core initiation machinery is consistent with the observed biochemically defined steps and could satisfy a biological requirement for dynamic regulation. However, we now understand that the RNA Pol II core initiation machinery is more elaborate than previously anticipated and contains up to 40 polypeptides comprising just the separable activities that govern the distinct steps leading to transcription described above. When combined with the profusion of additional co-factors observed to interact with the core machinery and required to regulate activated transcription (Inostroza et al. 1992; Kim et al. 1994; Nakajima et al. 1997), the assemblage that may represent an initiation complex could be extraordinarily large (Fig. 2B,C). It would appear to be inefficient for regulators to individually recruit and organize such a complex assembly within the time scales necessary at each promoter in the cell. This notion is supported by the limited cellular concentration of many of these factors relative to the number of genes that must be transcribed and the modest binding affinities typically observed between these components and DNA targets, particularly in the context of chromatin (Imbalzano et al. 1994; Bushnell et al. 1996; for review, see Beato and Eisfeld 1997). Furthermore, not all sequence-specific binding factors interact directly with components of the transcription apparatus and vice versa. The task of stepwise recruitment of the initiation machinery by activators becomes especially daunting considering the requirement for additional peripheral co-regulator activities necessary to navigate transcription through chromatin (Table 1 and 


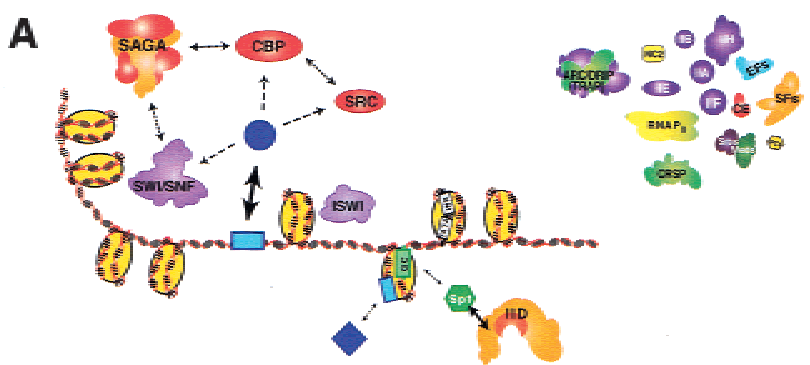

Chromatin Remodeling/Template Access
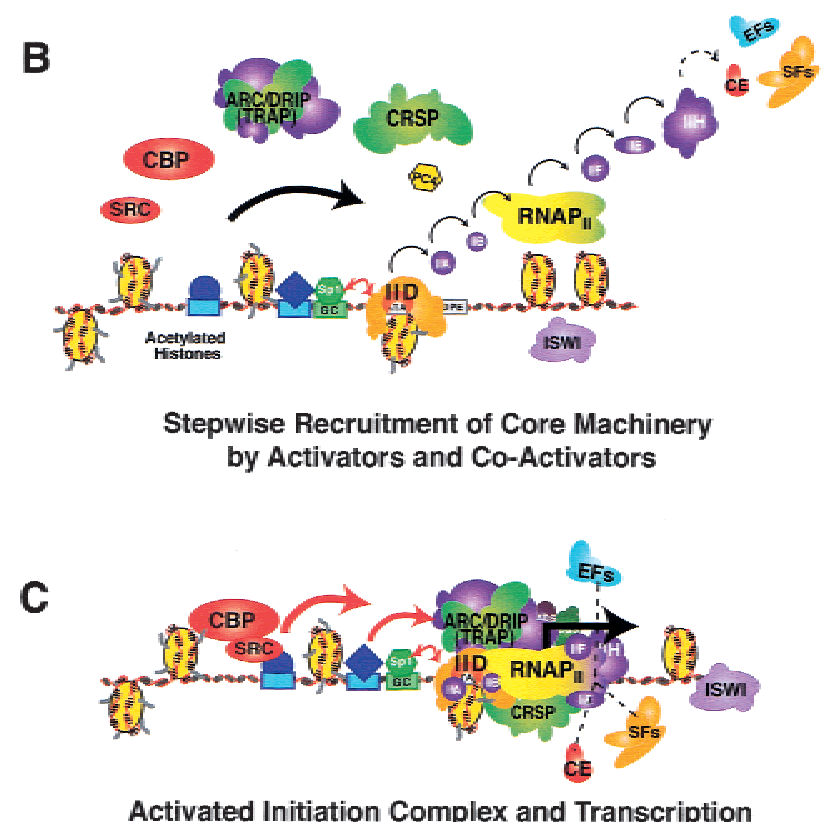

Figure 2. A stepwise assembly model for transcription initiation. (A) Depicted are cooperative chromatin remodeling events (left) induced by ATP-dependent factors (purple) and histonemodifying acetyltransferase activities (red and orange) through their interactions (broken arrows) with each other and some transcriptional regulators (blue circle) that have access (thick arrow) to specific DNA sequences through gene-specific nucleosome positioning effects. The core machinery and some co-factors that act at subsequent steps are depicted as a pool to the right. (B) Such chromatin remodeling events could lead to nucleosome shifting relative to specific target sequences as well as histone acetylation (grey lines), which together likely allow full template accessibility to other transcription factors (blue diamond and Sp1, green hexagon) and the core machinery (right). A large body of biochemical studies suggests that activators and their co-regulators can interact (thick black arrow) with multiple components of the core initiation machinery; however, the in vitro reconstitution of promoter binding and transcription initiation requires a specific ordered assembly (small black arrows) with defined biochemical steps (see text). (C) Activated transcription (black arrow) requires the assembly of a large oligomeric initiation complex and, likely, multiple concerted signals (red arrows) from several gene regulators. Association of RNA processing factors [i.e. capping enzyme (CE, red), elongation factors (EFs, cyan), and splicing factors (SFs, orange)] with the initiation complex requires additional signals including, but not limited to, hyperphosphorylation of RNA Pol II (yellow, purple shading). For further discussion and references, see text.
Fig. 2A; for review, see Struhl 1998; Kingston and Narlikar 1999). Are all of the reported interactions between regulators, co-regulators, and the core machinery necessarily important for the assembly of an initiation complex at a particular promoter? While many of the highaffinity interactions are certainly important, it is plausible that other interactions may occur only in select contexts or, possibly, that some of these interactions may be inconsequential and recruitment is indirect. Collectively, these notions and other observations discussed below have led some investigators to justly question the stepwise assembly model.

\section{A pre-assembly model}

Another popular but diametrically opposite model for transcription initiation envisions the targeted recruitment of a completely pre-assembled RNA Pol II holoenzyme (Fig. 3 and below). This model was first proposed when certain preparations of RNA Pol II were observed to co-purify with subsets of the basal machinery along with some co-regulators, including chromatin remodeling factors such as SWI/SNF and CBP, and even proteins involved in DNA replication and repair (Koleske and Young 1994; Chao et al. 1996; Maldonado et al. 1996; for review, see Parvin and Young 1998). Despite considerable heterogeneity of these RNA Pol II preparations, one

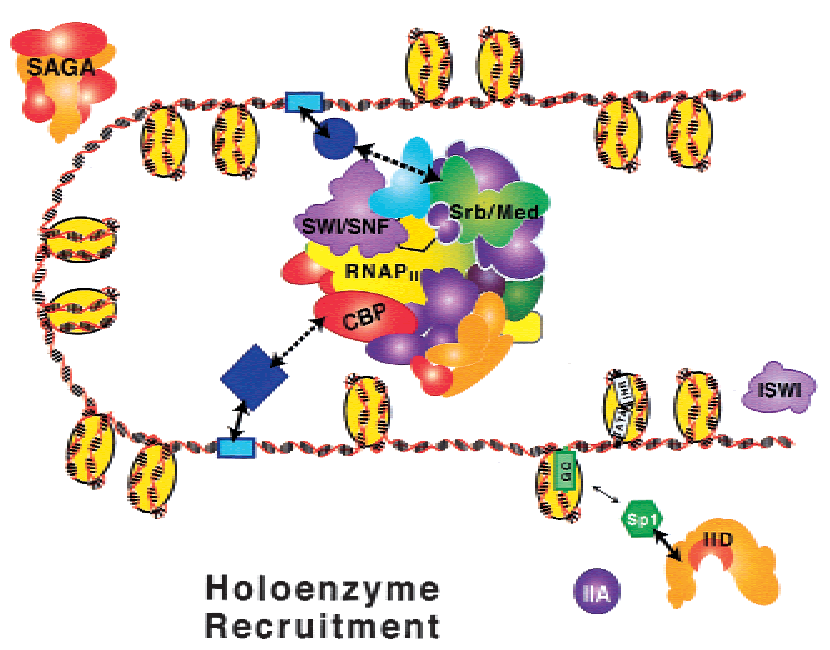

Figure 3. A pre-assembly model for transcription initiation. Depicted is the recruitment of a holoenzyme (i.e., a complex containing chromatin remodeling factors, multiple co-regulators, RNA polymerase, the core initiation machinery, and RNAprocessing factors) via cooperative interactions with several gene regulators. This RNA polymerase holoenzyme complex has variously been defined to contain multiple SRB and Med polypeptides as well as SWI/SNF and CBP, the two latter components documented to be responsible for chromatin remodeling. By contrast, TBP, TAFs, and TFIIA have not been observed to co-purify with these holoenzyme preparations, thus TFIID and SAGA as well as TFIIA are excluded. With such a preassembled holo-complex model, at least two steps are required involving separate recruitment of RNA Pol II plus associated activities (center) and TFIID (bottom right). 
invariant property has been the absence of TFIID in these holoenzyme conglomerates. Consequently, minimally two targeted steps are required to form an active preinitiation complex with the holoenzyme model as recruitment of TFIID (or a functional equivalent) is a prerequisite for transcription. One possible advantage to a holo-complex is the ability to obviate the limited cellular concentration of individual transcription factors. A pre-assembled RNA polymerase complex could, in principle, facilitate rapid responsiveness to arrayed regulators that might cooperatively recruit the transcriptional machinery via targeting of multiple interfaces. On the other hand, the recruitment of a monolithic universal holoenzyme does not fit well with the observed need for the vast diversity of co-regulators in animal cells. We contend it would be more favorable to employ multiple regulators that act at different stages of the transcription reaction. Such a multi-faceted mechanism could impose controls at different barriers to the transcription process and thereby provide greater flexibility and fine tuning to rates of transcription. By contrast, a system that relied on the recruitment of a holo-complex would seem to be less effective in accommodating dynamic regulation of transcription in response to small variations in the concentration of individual cellular regulatory factors.

A holoenzyme model becomes more disadvantageous when considering the wealth of biochemical evidence that suggests elongating RNA Pol II complexes are distinctly different from those responsible for initiation of transcription (Zawel et al. 1995; for review, see Reines et al. 1999). If a pre-formed holo-complex were responsible for initiation, then, presumably, the transcribing complex would have to shed components that must then be recycled into new holoenzymes or, otherwise, would be subject to degradation, de novo synthesis, and re-assembly. Because eukaryotic polymerases are processive enzymes, such a scenario would require the recruitment of additional holoenzymes to each promoter for each reinitiation event. Such a mechanism appears inconsistent with the significantly greater number of RNA Pol II molecules relative to other components of the core initiation complex in cells (Kimura et al. 1999). Furthermore, evidence appears to be mounting for an ordered progression of chromatin remodeling events that temporally segregates the requisite co-regulators from the transcription machinery. This latter aspect further erodes the notion that a holoenzyme complex inherently containing everything needed to both remodel chromatin and initiate transcription is pre-assembled.

Compelling evidence in support of the sequential requirement for multiple co-regulators and their ordered interplay has come from elegant studies of the $\mathrm{HO}$ endonuclease gene in yeast. Blocks to cell cycle progression combined with chromatin immunoprecipitation (ChIP) experiments in various genetic backgrounds revealed the epistasis of events required for expression of this gene (Cosma et al. 1999; Krebs et al. 1999). It was determined that occupation of upstream sequences by a primary enhancer-binding factor preceded chromatin remodeling events requiring SWI/SNF followed by SAGA, which to- gether appeared to promote localized histone acetylation and enabled secondary regulators to access DNA targets. Perhaps most intriguing, chromatin remodeling and histone acetylation at the promoter did not require the presence of promoter proximal regulators; however, these remodeling events were insufficient for gene expression which required further action by a set of secondary regulators. Thus, chromatin remodeling preceded recruitment of RNA Pol II. By inference, because transcription was uncoupled from chromatin remodeling, SWI/SNF and other chromatin remodeling activities are not likely to be intrinsic constituents of a Pol II holoenzyme.

Other ATP-dependent chromatin remodeling- and histone modifying-activities likely act in concert at targeted genes and their relative requirements may be regulatordependent and dictated by sequence positioning effects as well as overall chromatin organization. Consistent with this notion, proper steroid-responsiveness from the well-characterized MMTV-LTR in mammalian cells appears to require both SWI/SNF recruitment and genomic integration of this gene into chromatin (Fryer and Archer 1998). These results, together with others not discussed here, suggest that specialized binding sites in chromatin are accessible to primary activators but the involvement of secondary activators is dependent on chromatin remodeling and modification by co-regulators directly recruited by primary regulators. It is the secondary activators that likely direct gene transcription through multiplicative interactions with some requisite co-factors, promoter-selectivity factors, and the core machinery. Not only have chromatin remodeling and transcription events been uncoupled but, most intriguingly, even recruitment of RNA polymerase to certain promoters in vivo appears to be insufficient to trigger transcriptional activation. It is well documented that the HSP70 promoter contains an engaged but stalled RNA polymerase molecule that requires heat shock factor for events subsequent to RNA Pol II recruitment to activate the gene (Rougvie and Lis 1988; for review, see Lis and Wu 1993). More recent studies have proposed that one way in which glucocorticoids may suppress immune function is through transcriptional interference by direct association of GR with DNA-bound RelA, an NF-кB family member responsible for activation of pro-inflammatory genes. ChIP analysis determined that GR-dependent transcriptional interference occurred subsequent to RNA Pol II and TFIIH association with Rel A-occupied target genes at a step involving selective phosphorylation of RNA Pol II (Nissen and Yamamoto 2000). Thus, although each may be necessary, the simple binding of an activator and the subsequent recruitment of RNA Pol II to the promoter is not sufficient to adequately describe the transcription activation process in eukaryotes.

\section{If not stepwise nor holoenzyme, then what?}

Because the basal machinery and co-regulator activities are separable and can be reconstituted biochemically with distinct rate-limiting steps, it seems more likely that there are multiple stages employed by sequence- 
specific DNA-binding factors to exercise regulation in vivo that cannot be explained by the simple binary recruitment of an RNA Pol II holoenzyme. This does not require, nor do we suggest, that individual polypeptides of the entire pre-initiation complex be recruited to and assembled de novo at each promoter in the cell. Some components of the core machinery almost certainly preexist as tightly associated complexes such as TFIID, TFIIH, and core RNA Pol II itself. It seems reasonable to postulate that eukaryotes have evolved adaptable and interchangeable transcription complex modules along with attendant co-regulators incorporating subsets of multifunctional polypeptides. Selective engagement of such modules within this network at required stages in the transcription process could effectively coordinate the actions of multiple gene-specific factors in response to the often subtle regulatory signals that control the highly restricted expression of complex genomes.

Cytological studies suggest that some co-regulators and components of the general machinery may be segregated from each other in the nucleus (Reyes et al. 1997). Considering the problem of limited factor concentration in the nucleus and the important role of chromosomal context for transcription of some genes, it is possible that gene regulatory systems have evolved as organized compartments in the nucleus containing increased local concentrations of select co-regulators and subsets of the transcription machinery. To consider how genes may be regulated in their native chromatin context and to contemplate how these events could be coordinated, we now take into account previous notions and recent evidence that the nucleus is highly organized and possibly functionally subdivided in accordance with the transcriptional requirements of a given cell type.

\section{Organization of the nucleus: Implications for compartmentalization of transcription}

It is well-documented that the nucleus contains a visible fibrous network consisting of ribonucleoproteins, lamins, actin, and a myriad of other uncharacterized proteins (for review, see Pederson 1998). This so-called nuclear matrix may then be analogous to the cytoskeleton responsible for structural integrity and cell function. It was recently established that individual chromosomes are epigenetically organized into territories that condense and decondense in a cell cycle coordinated fashion (Ferreira et al. 1997; Croft et al. 1999; Sadoni et al. 1999). It also appears that transcriptionally active genes are generally oriented toward the center of the nucleus within individual chromosome territories, while silenced genes are arranged near the periphery of the nucleus (Andrulis et al. 1998; Verschure et al. 1999). In addition, there is evidence to suggest that euchromatin is more closely associated with structures of the nuclear pore complex that extend into the nuclear space while heterochromatin is more confined to sites distal to the pores (G. Blobel, pers. comm.). Although metaphase chromatin is highly condensed, interphase chromatin is variably de-condensed including loops of 30 -nm fibers with matrix or scaffold attachment sites referred to as MARs or SARs. These nuclease-accessible, often AT-rich sequences, can be separated by tens or hundreds of kilobases and may encompass clusters of regional cis-regulatory elements (Cockerill and Garrard 1986; Gasser and Laemmli 1986; Forrester et al. 1994). Some regulatory elements suggested to be SARs/MARs have been proposed to act as insulators by segregating transcriptionally active regions of chromatin from silent heterochromatic regions (Girard et al. 1998; Namciu et al. 1998). These or other similar regulatory elements and chromatin- or nuclear matrix-associated factors may then serve to protect and promote an open or accessible chromatin domain, which could be important in regulating cell type-specific transcription (Kirillov et al. 1996; Jenuwein et al. 1997). Taken together, these studies are consistent with the notion that transcriptionally competent genes might be localized to specific areas of the nucleus.

One of the most prominent manifestations of a functional nuclear compartment for transcription is the nucleolus, where rRNA synthesis and ribosome biogenesis occurs. Clusters of tandemly arrayed rRNA precursor genes from several chromosomal sites become associated with the RNA Pol I machinery and rRNA processing apparatus to form the nucleolus (for review, see Fakan and Hernandez-Verdun 1986; Scheer and Hock 1999). Other types of cell cycle-modulated higher order nuclear domains have also been observed including speckles, interchromatin granule clusters, B-snurposomes, coiled or Cajal bodies, and PML bodies or PODs (Gall et al. 1999; for review, see Lamond and Earnshaw 1998; Matera 1999|. These potential nuclear compartments have been associated with various transcription factors, co-regulators, RNA polymerases, and RNA-processing factors. The functional significance of these bodies remains uncertain as they could represent active enzymatic centers or, alternatively, transcriptionally inert reservoirs for factors destined for degradation or recycling. Some transcription and processing factors appear to be associated with select foci and not others (Gall et al. 1999; for review, see Matera 1999). Unfortunately, however, the location(s) of some important but more recently identified regulatory factors has not been determined, and the exact molecular constituents of these sites remains poorly understood. Nevertheless, there is evidence to suggest that transcription of some co-localized snRNA genes occurs in a perinucleolar compartment while transcription of other snRNA genes is segregated into other nuclear areas (Huang et al. 1998; Pombo et al. 1998, 1999). Furthermore, there are reports that active RNA Pol II transcription occurs in a few thousand discrete foci in isolated nuclei as visualized by immunofluorescence and three-dimensional confocal microscopy (Zeng et al. 1997; Wei et al. 1999). It has been suggested that these foci represent individual transcription units (Zeng et al. 1997; Gall et al. 1999). Considering these observations, we speculate that there may be an overarching network of active centers organized to help direct complex regulated processes inherent to transcriptional activation. 
If there is a systematic organization to the metazoan nucleus, chromosomes must be arranged to accommodate differential cell type-specific and temporal patterns of gene expression. Sequence-specific repressors and their associated co-regulators are likely to play an important role in organizing gene expression patterns. For example, the lymphoid-specific transcriptional regulators Ikaros, Helios and Aiolos interact with HDAC complexes and associate with some target genes in pericentric heterochromatin (Brown et al. 1997; Hahm et al. 1998; Kim et al. 1999|. Thus, these types of regulators and associated co-regulators together may actually recruit some target genes to heterochromatin, perhaps as a way to maintain tissue-restricted patterns of repression. Although recruitment of genes to transcriptionally inactive space within chromosome territories seems tangible, nuclear organization is also likely to directly influence and perhaps participate in recruiting genes to active centers for transcription. For example, the observed punctate sites for Pol II transcription could represent compartments to which genes may be actively recruited via directed mobilization of the nuclear matrix. To consider this possibility, we return to the broader question of how a gene is turned on in a cell.

\section{A speculative model: Integrating nuclear compartments and specialized factories for transcription}

A recent study examined activation of reporter genes stably integrated into a homogeneously staining heterochromatic region in response to an inducible heterologous activator in human cells. Remarkably, a 100-Mb region was observed to de-condense within minutes upon induction of the transcriptional activator while a DNA-binding domain alone failed to promote this largescale chromosomal alteration (Tumbar et al. 1999). This extended de-condensation occurred in the absence of active transcription, suggesting that chromatin remodeling events may naturally take place prior to transcription. Such ordered events are directly analogous to the chromatin remodeling events observed with studies of the yeast HO gene described previously (Cosma et al. 1999; Krebs et al. 1999). Specific HAT activities were observed in a punctate pattern throughout the nucleoplasm and specifically associated with this de-condensed region (Tumbar et al. 1999). In other studies, the ATP-dependent remodeling complex SWI/SNF was observed to localize in a similar pattern of discrete punctate foci. Interestingly, SWI/SNF appears to selectively associate with the nuclear matrix and nuclease accessible chromatin during the $S$ and G2 phases of the cell cycle when SWI/SNF is not mitotically inactivated by phosphorylation (Reyes et al. 1997; Sif et al. 1998). These studies and others not discussed here are consistent with the notion that genes might first undergo an early chromatin rearrangement event through initial interactions with transcriptional activators and some chromatin-associated remodeling factors. It is also possible that some genes may be epigentically organized to be competent for activation. Recent studies with human $\beta$-globin transgenes in mouse cells have found a requirement for an intact enhancer in the suppression of silencing effects through exclusion of these transgenes from heterochromatin and have further correlated histone acetylation of these genes with this exclusion (Francastel et al. 1999; Schübeler et al. 2000). Physical separation from heterochromatin was independent of the $\beta$-globin LCR, yet localized histone $\mathrm{H} 3$-acetylation of both the promoter and the LCR appeared to be important for gene expression (Schübeler et al. 2000). Accordingly, after initial remodeling events, enhancer-binding factors could recruit other appropriate chromatin remodeling factors, some of which may be intimately associated with the nuclear matrix (Fig. 4A). Following DNA recognition by gene-specific regulators and subsequent chromatin remodeling events, the proper transcription machinery must be assembled at the promoter. Thus, the targeting of specific genes to select sites in the nuclear matrix may, in turn, allow the formation of (or recruitment to) specialized transcriptionally active compartments within chromosome territories.

Are the different bodies and particles observed by microscopy and immunofluorescence structurally and functionally equivalent or could there be distinct functions associated with different nuclear addresses? It seems reasonable to postulate that gene-specific DNA sequences will, in part, dictate the targeted recruitment of transcriptional promoters to select functional compartments. Gene promoters inherently contain information to distinguish functional specificity. This notion was originally established by the characterization of $\sigma$ factors in prokaryotes and the separation of three enzyme systems for transcription in eukaryotes. The finer points of control in the mechanisms governing core promoter recognition in eukaryotes, however, are only now coming into view. To consider how the targeting of promoters to select areas in the nucleus might be important for integrating the temporal assembly of the transcription machinery, we first describe some key elements of eukaryotic promoter recognition and the discovery of diversity and specialization of the core machinery.

The first hint of core promoter selectivity in eukaryotes came when TAFs in the TFIID complex were found to be involved in start site selection and recognition of initiator and downstream promoter elements for transcription by RNA Pol II (Pugh and Tjian 1991; Hansen and Tjian 1995; Burke and Kadonaga 1996). This observation suggested that, at some genes, TBP may not play the central role in DNA recognition by TFIID but instead that the TAF subunits may govern promoter recognition. Direct evidence for promoter selectivity by TAFs was obtained with the demonstration that specific TAFs $(250,150$, and 60) recognize initiator elements and downstream promoter elements found in many metazoan genes transcribed by RNA Pol II (Verrijzer et al. 1994, 1995; Burke and Kadonaga 1997; J.T. Kadonaga, pers. comm.). Furthermore, other distinct TAF subunits that are intrinsic components of promoter-selectivity complexes utilized by RNA Pol I and Pol III (i.e., SL1 and $\mathrm{SNAP}_{\mathrm{c}}$ ) were also found to be important for promoter 
A

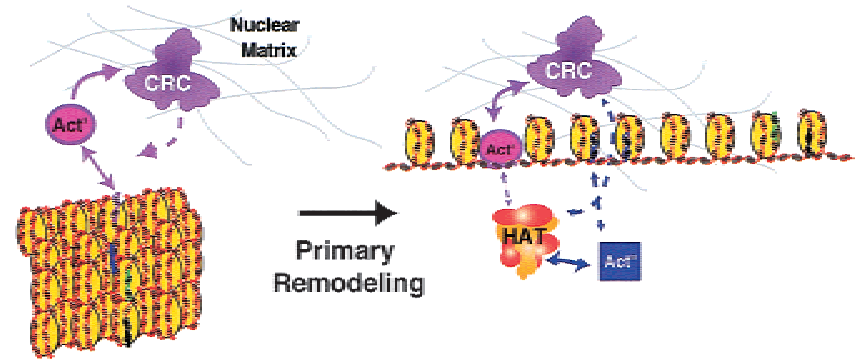

B

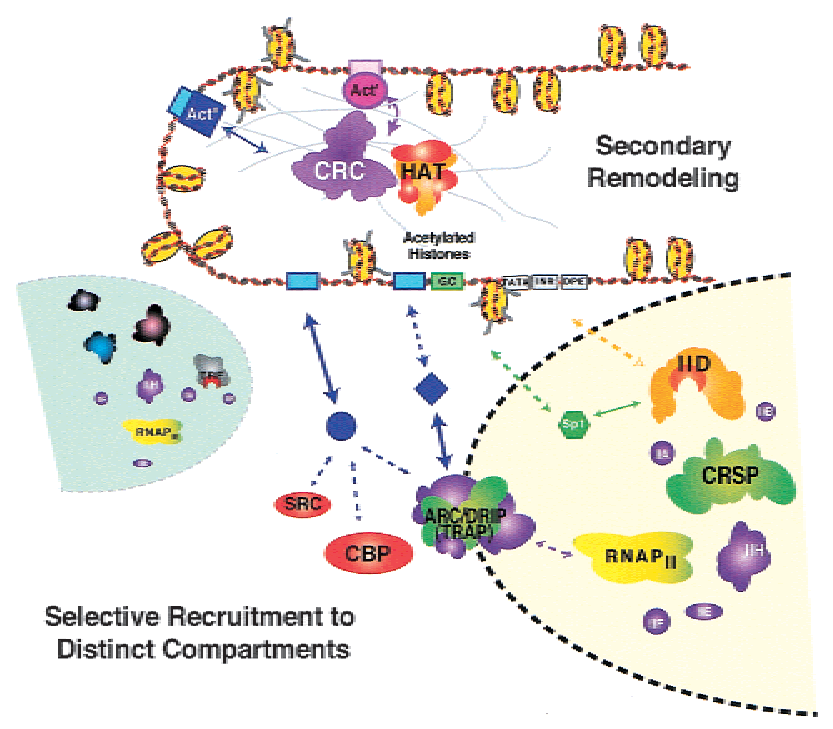

C

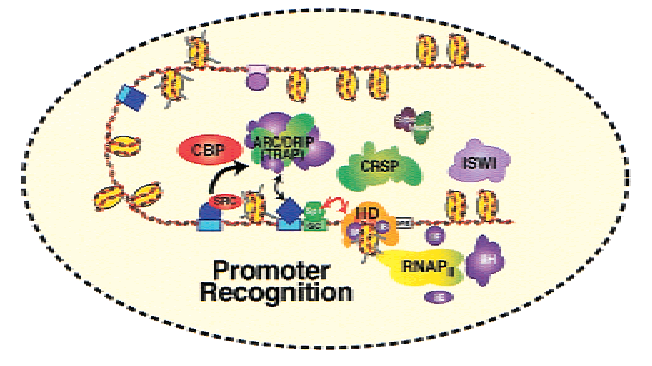

D

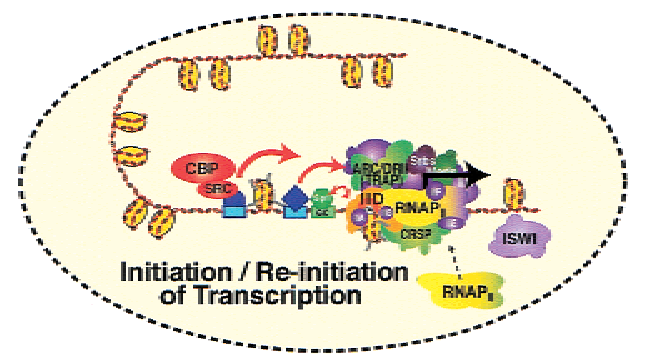

E

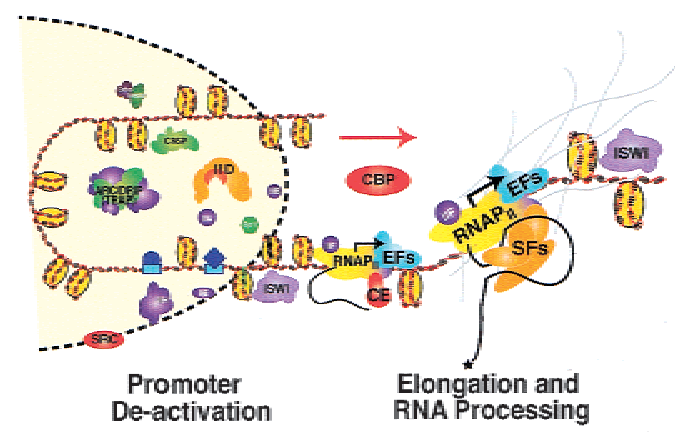

Figure 4. A speculative signal-mediated transfer model that attempts to integrate nuclear compartmentalization and transcription. (A) Depicted are regional chromatin remodeling events that most likely occur with (left) 30-nm and (right) 10-nm chromatin fibers, following initial large-scale chromatin unfolding events (not shown). (left) Primary activators (Act', pink) with some limited DNA target accessibility in the 30-nm chromatin fiber could enlist chromatin remodeling complexes (CRC, purple) associated with the nuclear matrix (grey webbing) to promote accessibility to specific DNA elements targeted by secondary activators (Act" ${ }^{\prime}$, blue square). (Right) Opening of such target sites might then enable cooperative interactions between these activators and additional chromatin modifying activities, including histone acetyltransferases (HAT, red and orange). (B) (Top) Secondary chromatin remodeling including nucleosome shifting and histone acetylation could provide DNA target site access to other activators (blue circle and diamond). Acetylation of histones overlapping core promoter elements in chromatin might provide a signal for promoter recognition by selectivity factors such as TFIID (for full discussion, see text). Subsequent cooperative interactions between sequence-specific activators, co-regulators and perhaps mobilization of the nuclear matrix could together promote the directed association of an activated promoter with a select transcription factory or compartment in the nucleus. According to this model, proximal enhancer and core promoter sequences might also direct selective recruitment to an Sp1- and TFIID-containing compartment (bottom right, yellow) as opposed to a nearby TRF-containing compartment (bottom left, green). (C) Following selective recruitment to a localized transcription factory, cooperative interactions between sequence-specific regulators and co-regulators could initiate promoter binding and subsequent events leading to the formation of an active initiation complex. (D) Transcription initiation (black arrow) and re-initiation (shown as entry of additional molecules of RNA Pol II) might then be promulgated by concerted signals (red arrows) from gene-specific regulators and their dynamic interactions with DNA targets and co-regulators. Subsequent events might signal for promoter de-activation. $(E)$ Disassembly of the initiation complex and release or transfer of the DNA template from the transcription initiation factory to other functional compartments may facilitate elongation and RNA processing. CBP/p300 has been found to interact with and modify numerous transcription components to both enhance and attenuate transcription. Hypothetically, these and other co-regulators could serve as links (red arrow) to sequential stages in the transcription reaction-perhaps even as chaperones between designated nuclear areas such as transcription factories and RNA-processing compartments (not shown).

recognition (Beckmann et al. 1995; Henry et al. 1998). A growing body of evidence both in vitro and in vivo from yeast to man support the conclusion that TAFs contribute to activator-mediated transcription and participate in directing core promoter recognition (Holstege et al.
1998; Michel et al. 1998; Komarnitsky et al. 1999; for review, see Goodrich et al. 1996; Green 2000). Because these interactions are integral to the assembly of transcription initiation complexes, promoter-selectivity factors and sequence-specific DNA-binding regulators 
could collectively combine to designate potentially important elements in establishing nuclear compartments for transcription.

Some gene-specific regulators are sequestered in the cytoplasm or are otherwise inactivated and require signal transduction to instigate transcription (Baeuerle and Baltimore 1988; Picard et al. 1988). However, other sequence-specific activators that cooperate with the signal-responsive regulators are constitutively nuclear (such as Sp1). A subset of these types of regulators may themselves designate the functional specificity of a given nuclear compartment by their chromatin-limited association with DNA target sequences and their interactions with modules of promoter selectivity factors (such as IID) and co-regulators (such as CRSP). Therefore, by analogy to the nucleolar organizer, perhaps genes that require Sp1, TAF130-containing TFIID, and CRSP are colocalized to a nuclear compartment populated with a defined subset of the transcription machinery (Fig. 4B, yellow compartment). Other promoter-selectivity factors might be similarly partitioned into distinct loci containing a different collection of co-factors and transcription complexes. For example, such specialized compartments for RNA Pol II transcription might contain TBP-TAF complexes with tissue-restricted TAFs, such as the Bcell TAF105, to which certain genes might be selectively recruited.

In addition to specialized TAFs, there are also the TBPrelated factors, TRF1 and TRF2 (Crowley et al. 1993; Hansen et al. 1997; Rabenstein et al. 1999), that could be pre-localized and thereby provide additional compartment-specific activities capable of promoter selectivity in metazoans. Reports of transcription initiation in the absence of TBP in vitro suggest the long held notion that TBP-containing complexes are the sole and universal promoter-recognition factors must be reconsidered (Usheva and Shenk 1994; Wieczorek et al. 1998; Takada et al. 2000). Notably, a complex containing the tissue-restricted factor TRF1 may play an important role in directing Pol III-dependent transcription in Drosophila (Takada et al. 2000). Other recent results indicate that TRF1 recognizes a TC-rich DNA sequence in place of the TATA element recognized by TBP (Holmes and Tjian 2000). Interestingly, this study found that one TRF1 target gene utilizes two tandem promoters transcribed by RNA Pol II-one directed by TRF1 and another that responds to TBP. Although considerably less well characterized, it seems clear that TRF2 fails to recognize TATA sequences (Dantonel et al. 1999; Rabenstein et al. 1999). By analogy to TBP and TRF1, it could be expected that TRF2 and associated polypeptides recognize other as yet undetermined DNA sequences to direct transcription at specific classes of promoters. We hypothesize that these promoter-selectivity factors might be associated with distinct co-regulators and be segregated into different functional regions within a chromosome territory (Fig. 4B, green compartment).

Each cell may then require multiple types of transcriptionally active nuclear domains designated by the cooperative interactions of particular regulators and co-regu- lators. It is also possible that the cell might somehow detect active centers of transcription within a specific area of the nucleus and thus direct or modulate assembly of the appropriate transcription components within such compartments. The cell might even direct newly synthesized subsets of co-regulators and specialized components of the transcriptional machinery to the targeted sites as they are needed. Target genes competent for transcription could themselves be oriented in such a way as to be in close proximity to nuclear pores. In fact, multiple distinct nuclear importin or karyopherin molecules that function as chaperones appear to selectively associate with different transcription factors and thus could be instrumental in ferrying them to the proper sites (Pemberton et al. 1999; Titov and Blobel 1999).

\section{Transcription by modular signal-mediated transfer}

In addition to recognition of specific promoter/enhancer DNA sequences, there could be other important elements of transcriptional selectivity and assembly of initiation complexes. For many genes, the acetylation state of chromatin has long been correlated with their expression and these modifications have generally been proposed to loosen chromatin structure. However, posttranslational modification (acetylation, methylation, phosphorylation, etc.) of chromatin may not only enable transcription factors to access their DNA targets, but also may act as specific molecular signals for DNA recognition (for review, see Strahl and Allis 2000). Therefore, specific covalent modification of chromatin subunits (i.e., histones) might serve as a docking site for select transcription complexes. There is some evidence for recognition of a particular acetylation state by coregulators such as the SIR complex, in part responsible for the formation and maintenance of heterochromatin in yeast (Hecht et al. 1995; Braunstein et al. 1996; Rundlett et al. 1996). Additonally, phosphorylation of histone $\mathrm{H} 3$ tails increase its recognition as a substrate for the GCN5 acetylase while both modifications are correlated with increased transcription in yeast and mammalian cells (Cheung et al. 2000; Lo et al. 2000). Recent studies suggest there may be a role for specific histone acetylation in core promoter recognition by TFIID. X-ray structural analysis combined with quantitative binding assays revealed that the double bromodomain of TAF250 specifically recognized a di-acetylated histone $\mathrm{H} 4$ tail peptide but not a control acetylated peptide (Jacobson et al. 2000). Importantly, these interactions exhibited one to one stoichiometry and were undetectable with an unacetylated histone $\mathrm{H} 4$ tail peptide. Interestingly, recent low-resolution structures of the holo-TFIID complex revealed a cavity large enough to accommodate the binding of a nucleosomal substrate (Andel et al. 1999; Brand et al. 1999). Thus, in contrast to previous assumptions, TFIID may not require binding to naked DNA but may instead interact specifically and intimately with appropriately modified chromatin templates (Fig. 4B). As a further extension of these findings, one might envisage that such activated promoters are recruited to transcription 
compartments through cooperative protein-DNA interactions that, in the case of TFIID, may involve recognition of a specific histone acetylation pattern (Fig. 4C). Once localized to such compartments, transcription of an activated promoter could be efficiently instigated by cooperative signals between sequence-specific transcription factors, co-regulators, and the core machinery (Fig. 4D).

There is scant evidence to support nuclear compartmentalization of RNA Pol II transcription as proposed herein. However, there are a number of recent observations that are more consistent with the notion of territorial subdivision than the mass action competition for factors inherent to stepwise assembly and holoenzyme models. One study surprisingly revealed that ligand-dependent promoter remodeling, co-activator association, and target gene transcription induced by nuclear receptors are remarkably transient (minutes) despite continuous receptor association with the target DNA (hours) (Chen et al. 1999). A mechanism for this de-activation was suggested to be p300 co-activator-dependent acetylation of another co-factor in the p160 family, thus preventing its association with nuclear receptors. A similar observation was made for the attenuation of transcription through the CBP co-activator-mediated acetylation of an architectural transcription factor, HMGI(Y), that appears to be required for stabilization of an enhanceosome (Munshi et al. 1998). If, as these studies suggest, post-translational modification and inactivation of transcription factors are important for down-modulation of gene expression, a nuclear compartmentalization model is most attractive and is supported by further arguments presented below.

Biological systems are dynamic and transcription factors likely only transiently associate with their cognate DNA recognition sites and co-factor targets $(\mathrm{McNally}$ et al. 2000). If a cell were to inactivate the entire cellular pool of a given co-activator or activator in response to one signal, such a mechanism would preclude responsiveness by other activators or cooperativity at other genes in response to additional signals. However, if transcription complexes are assembled within segregated nuclear compartments, then inactivation, transient or otherwise, of the few resident molecules of a particular transcription factor within the designated compartment could take place without affecting the same factors in other compartments associated with different genes. Furthermore, it could be advantageous for a cell to initiate transcription in one compartment and then, upon de-activation signals, release the promoter or even translocate the RNA polymerase-associated template to adjacent nuclear compartments to facilitate elongation and RNA-processing events.

Transcription and RNA processing appear to be coupled and specific phosphorylation signals are thought to be requisite for association of additional factors with the RNA Pol II CTD to carry out post-initiation events (Misteli et al. 1998; Ho and Shuman 1999; for review, see McCracken et al. 1998). Quantitative cytological studies have found that nuclear speckle domains with high con- centrations of splicing factors are regionally stationary, but movement at their periphery appears to be highly dynamic and dependent on active transcription (Eils et al. 2000). Although still poorly understood, there appears to be gene-selective association with these speckle domains (Smith et al. 1999; Wei et al. 1999). Because transcription from some genes is transient, promoter de-activation or other signals might initiate template exchange to other nuclear areas for efficient transcript extension and processing (Fig. 4E).

In considering localized transcription factories, we envisage the DNA template being pulled through matrixassociated RNA Pol II complexes that are themselves capable of interacting with different modules of co-regulators and RNA-processing machinery. We postulate that there may be a progressive signal-mediated assembly line mechanism for Pol II transcription. By this notion, the DNA template could be passed from: (1) nuclear matrix-associated chromatin remodeling co-regulators, to (2) promoter recognition factors within transcription initiation compartments and, following promoter de-activation, transferred to (3) elongation and processing compartments each selectively organized within the interchromatin space (Fig. 4). We propose that these designated nuclear areas exist to provide an increased local concentration of certain factors to more efficiently carry out the transcription process for many or even most genes. In doing so, we do not advocate that all genes must be expressed in this manner, nor do we expect the biochemical stages inherent to transcription exclusively occur in one compartment and not another. For example, for re-initiation to occur at a given promoter, the preceding polymerase molecule must enter the early elongation phase. We would, therefore, expect that initiation compartments also contain a limited amount of RNA-processing factors. Moreover, we would predict that there is some free exchange of transcription factors with surrounding areas. Taken together, these notions are consistent with cytological studies that have generally found high concentrations of select factors in discrete foci, yet diffuse lower concentrations throughout the nucleoplasm. We expect that when the subnuclear distributions of many other transcriptional regulators and coregulators are determined, the functionality of segregated compartments could be illuminated.

\section{Conclusions}

The evolution of complex cellular and developmental processes depends on the maintenance and regulation of large amounts of genetic information. Eukaryotic cell propagation necessarily requires an integrated process for the fidelity of DNA replication and its proper segregation to daughter cells. Although the fundamental order of these processes could be visualized by cell biologists for nearly a century, we now find a macroscopic picture for gene expression may also be emerging. Recent experiments suggest there is an ordered progression of events leading to gene expression catalyzed by select activatorand repressor-recruited transcriptional co-regulators, 
some of which have been observed to exist in discrete segregated nuclear foci. Moreover, there now appears to be an expansion of core promoter recognition factors in metazoans that may exert their transcriptional effects at completely different subsets of genes. From these collective observations, we have proposed that different classes of co-regulators may be segregated within distinct compartments of the nucleus and that enhancerbinding factors and specific DNA sequences, in part, direct the sequestration of genes to active centers via interaction with promoter selectivity factors.

It is our understanding that eukaryotes have adopted interchangeable subsets or modules of polypeptides with related functions to create families of multifunctional transcription factors. With such a system, many layers of control can be achieved with a minimal number of polypeptides and, importantly, without the requirement that all genes be expressed in the same way. Furthermore, such an intricate network for gene expression provides the plasticity required by metazoans to respond to developmental and environmental cues. Just as mitosis is an elegant orchestrated cellular process, it would not be surprising to find that eukaryotic RNA synthesis and processing is compartmentalized into stages that themselves are interdependently regulated. Such a locationdependent transcription process would be in contrast to the now conventional view in which regulation is achieved by a competition for limiting circulating factors evenly dispersed in the nucleoplasm followed by their recruitment to specific gene promoters. We anticipate that a greater appreciation for the intricacies of metazoan gene expression will only be realized by continued efforts to examine the actions of cellular regulatory factors on bona fide target genes in vivo in conjunction with biochemical reconstitution of the transcription reaction in the context of more physiologically relevant chromatin template systems.

\section{Acknowledgments}

We thank M. Biggin, M. Botchan, R. Freiman, A. Hochheimer, R. Jacobson, J. Kadonaga, A. Ladurner, A. Näär, D. Rio, D. Taatjes, S. Takada, and other members of our laboratory for their helpful comments, discussion, and critical review of the manuscript. We additionally thank G. Blobel, M. Fuller, J. Kadonaga, and K. Yamamoto for communicating results prior to publication. B. Lemon is supported by a National Research Service Award (GM-19325).

\section{References}

Andel, F., 3rd, Ladurner, A.G., Inouye, C., Tjian, R., and Nogales, E. 1999. Three-dimensional structure of the human TFIID-IIA-IIB complex. Science 286: 2153-2156.

Andrulis, E.D., Neiman, A.M., Zappulla, D.C., and Sternglanz, R. 1998. Perinuclear localization of chromatin facilitates transcriptional silencing. Nature 394: 592-595.

Baeuerle, P.A. and Baltimore, D. 1988. Activation of DNA-binding activity in an apparently cytoplasmic precursor of the NF-кB transcription factor. Cell 53: 211-217.

Bautz, E.K. and Bautz, F.A. 1970. Initiation of RNA synthesis:
The function of sigma in the binding of RNA polymerase to promoter sites. Nature 226: 1219-1222.

Beato, M. and Eisfeld, K. 1997. Transcription factor access to chromatin. Nucleic Acids Res. 25: 3559-3563.

Beckmann, H., Chen, J.L., O'Brien, T., and Tjian, R. 1995. Coactivator and promoter-selective properties of RNA polymerase I TAFs. Science 270: 1506-1509.

Bentley, D. 1999. Coupling RNA polymerase II transcription with pre-mRNA processing. Curr. Opin. Cell Biol. 11: 347351.

Boyer, T.G., Martin, M.E.D., Lees, E., Ricciardi, R.P., and Berk, A.J. 1999. Mammalian Srb/Mediator complex is targeted by adenovirus E1A protein. Nature 399: 276-279.

Brand, M., Leurent, C., Mallouh, V., Tora, L., and Schultz, P. 1999. Three-dimensional structures of the TAFII-containing complexes TFIID and TFTC. Science 286: 2151-2153.

Brandsen, J., Werten, S., van der Vliet, P.C., Meisterernst, M., Kroon, J., and Gros, P. 1997. C-terminal domain of transcription cofactor PC4 reveals dimeric ssDNA binding site. $\mathrm{Na}$ ture Struct. Biol. 4: 900-903.

Braunstein, M., Sobel, R.E., Allis, C.D., Turner, B.M., and Broach, J.R. 1996. Efficient transcriptional silencing in Saccharomyces cerevisiae requires a heterochromatin histone acetylation pattern. Mol. Cell. Biol. 16: 4349-4356.

Brown, C.E., Lechner, T., Howe, L., and Workman, J.L. 2000. The many HATs of transcription coactivators. Trends Biochem. Sci. 25: 15-19.

Brown, K.E., Guest, S.S., Smale, S.T., Hahm, K., Merkenschlager, M., and Fisher, A.G. 1997. Association of transcriptionally silent genes with Ikaros complexes at centromeric heterochromatin. Cell 91: 845-854.

Brownell, J.E., Zhou, J., Ranalli, T., Kobayashi, R., Edmonson, D.G., Roth, S.Y., and Allis, C.D. 1996. Tetrahymena histone acetyltransferase A: A homolog to yeast Gcn5p linking histone acetylation to gene activation. Cell 84: 843-851.

Buratowski, S. 1994. The basics of basal transcription by RNA polymerase II. Cell 77: 1-3.

Buratowski, S., Hahn, S., Guarente, L., and Sharp, P.A. 1989. Five intermediate complexes in transcription initiation by RNA polymerase II. Cell 56: 549-561.

Burke, T.W. and Kadonaga, J.T. 1996. Drosophila TFIID binds to a conserved downstream basal promoter element that is present in many TATA-box-deficient promoters. Genes \& Dev. 10: $711-724$.

. 1997. The downstream core promoter element, DPE, is conserved from Drosophila to humans and is recognized by TAFII60 of Drosophila. Genes \& Dev. 11: 3020-3031.

Burley, S.K. and Roeder, R.G. 1996. Biochemistry and structural biology of transcription factor IID (TFIID). Annu. Rev. Biochem. 65: 769-799.

Bushnell, D.A., Bamdad, C., and Kornberg, R.D. 1996. A minimal set of RNA polymerase II transcription protein interactions. J. Biol. Chem. 271: 20170-20174.

Carey, M. 1998. The enhanceosome and transcriptional synergy. Cell 92: 5-8.

Chao, D.M., Gadbois, E.L., Murray, P.J., Anderson, S.F., Sonu, M.S., Parvin, J.D. and Young, R.A. 1996. A mammalian SRB protein associated with an RNA polymerase II holoenzyme. Nature 380: 82-85.

Chen, G., Fernandez, J., Mische, S., and Courey, A.J. 1999. A functional interaction between the histone deacetylase Rpd3 and the corepressor groucho in Drosophila development. Genes \& Dev. 13: 2218-2230.

Chen, H., Lin, R.J., Schiltz, R.L., Chakravarti, D., Nash, A., Nagy, L., Privalsky, M.L., Nakatani, Y., and Evans, R.M. 1997. Nuclear receptor coactivator ACTR is a novel histone 
acetyltransferase and forms a multimeric activation complex with P/CAF and CBP/p300. Cell 90: 569-580.

Chen, H., Lin, R.J., Xie, W., Wilpitz, D., and Evans, R.M. 1999. Regulation of hormone-induced histone hyperacetylation and gene activation via acetylation of an acetylase. Cell 98: 675-686.

Chen, J.L., Attardi, L.D., Verrijzer, C.P., Yokomori, K., and Tjian, R. 1994. Assembly of recombinant TFIID reveals differential coactivator requirements for distinct transcriptional activators. Cell 79: 93-105.

Cheung, P., Tanner, K.G., Cheung, W.L., Sassone-Corsi, P., Denu, J.M., and Allis, C.D. 2000. Synergistic coupling of histone $\mathrm{H} 3$ phosphorylation and acetylation in response to epidermal growth factor stimulation. Mol. Cell 5: 905-915.

Chi, T., Lieberman, P., Ellwood, K., and Carey, M. 1995. A general mechanism for transcriptional synergy by eukaryotic activators. Nature 377: 254-257.

Cho, H., Orphanides, G., Sun, X., Yang, X.J., Ogryzko, V., Lees, E., Nakatani, Y., and Reinberg, D. 1998. A human RNA polymerase II complex containing factors that modify chromatin structure. Mol. Cell. Biol. 18: 5355-5363.

Cockerill, P.N. and Garrard, W.T. 1986. Chromosomal loop anchorage of the kappa immunoglobulin gene occurs next to the enhancer in a region containing topoisomerase II sites. Cell 44: 273-282.

Colgan, D.F. and Manley, J.L. 1997. Mechanism and regulation of mRNA polyadenylation. Genes \& Dev. 11: 2755-2766.

Conaway, R.C. and Conaway, J.W. 1993. General initiation factors for RNA polymerase II. Annu. Rev. Biochem. 62: 161190.

Cosma, M.P., Tanaka, T., and Nasmyth, K. 1999. Ordered recruitment of transcription and chromatin remodeling factors to a cell cycle- and developmentally regulated promoter. Cell 97: 299-311.

Côté, J., Quinn, J., Workman, J.L., and Peterson, C.L. 1994. Stimulation of GAL4 derivative binding to nucleosomal DNA by the yeast SWI/SNF complex. Science 265: 53-60.

Croft, J.A., Bridger, J.M., Boyle, S., Perry, P., Teague, P., and Bickmore, W.A. 1999. Differences in the localization and morphology of chromosomes in the human nucleus. J. Cell Biol. 145: 1119-1131.

Crowley, T.E., Hoey, T., Liu, J.K., Jan, Y.N., Jan, L.Y., and Tjian, R. 1993. A new factor related to TATA-binding protein has highly restricted expression patterns in Drosophila. Nature 361: 557-561.

Dantonel, J.C., Wurtz, J.M., Poch, O., Moras, D., and Tora, L. 1999. The TBP-like factor: An alternative transcription factor in metazoa? Trends Biochem. Sci. 24: 335-339.

Diamond, M.I., Miner, J.N., Yoshinaga, S.K., and Yamamoto, K.R. 1990. Transcription factor interactions: Selectors of positive or negative regulation from a single DNA element. Science 249: 1266-1272.

Dikstein, R., Ruppert, S., and Tjian, R. 1996a. TAFII250 is a bipartite protein kinase that phosphorylates the basal transcription factor RAP74. Cell 84: 781-790.

Dikstein, R., Zhou, S., and Tjian, R. 1996b. Human TAFII105 is a cell type-specific TFIID subunit related to hTAFII130. Cell 87: 137-146.

Dimova, D., Nackerdien, Z., Furgeson, S., Eguchi, S., and Osley, M.A. 1999. A role for transcriptional repressors in targeting the yeast Swi/Snf complex. Mol. Cell 4: 75-83.

Dynan, W.S. 1989. Modularity in promoters and enhancers. Cell 58: $1-4$.

Dynan, W.S., and Tjian, R. 1983. The promoter-specific factor $\mathrm{Sp} 1$ binds to upstream sequences in the SV40 early promoter. Cell 35: 79-87.
Dynlacht, B.D., Hoey, T., and Tjian, R. 1991. Isolation of coactivators associated with the TATA-binding protein that mediate transcriptional activation. Cell 66: 563-576.

Eils, R., Gerlich, D., Tvaruskó, W., Spector, D.L., and Misteli, T. 2000. Quantitative imaging of pre-mRNA splicing factors in living cells. Mol. Biol. Cell 11: 413-418.

Fakan, S. and Hernandez-Verdun, D. 1986. The nucleolus and the nucleolar organizer regions. Biol. Cell 56: 189-205.

Ferreira, J., Paolella, G., Ramos, C., and Lamond, A.I. 1997. Spatial organization of large-scale chromatin domains in the nucleus: A magnified view of single chromosome territories. J. Cell Biol. 139: 1597-1610.

Fondell, J.D., Ge, H., and Roeder, R.G. 1996. Ligand induction of a transcriptionally active thyroid hormone receptor coactivator complex. Proc. Natl. Acad. Sci. 93: 8329-8333.

Forrester, W.C., van Genderen, C., Jenuwein, T., and Grosschedl, R. 1994. Dependence of enhancer-mediated transcription of the immunoglobulin mu gene on nuclear matrix attachment regions. Science 265: 1221-1225.

Francastel, C., Walters, M.C., Groudine, M., and Martin, D.I. 1999. A functional enhancer suppresses silencing of a transgene and prevents its localization close to centromeric heterochromatin. Cell 99: 259-269.

Fryer, C.J. and Archer, T.K. 1998. Chromatin remodelling by the glucocorticoid receptor requires the BRG1 complex. Nature 393: 88-91.

Gall, J.G., Bellini, M., Wu, Z., and Murphy, C. 1999. Assembly of the nuclear transcription and processing machinery: Cajal bodies (coiled bodies) and transcriptosomes. Mol. Biol. Cell 10: 4385-4402.

Gasser, S.M. and Laemmli, U.K. 1986. Cohabitation of scaffold binding regions with upstream/enhancer elements of three developmentally regulated genes of D. melanogaster. Cell 46: $521-530$.

Ge, H. and Roeder, R.G. 1994. Purification, cloning, and characterization of a human coactivator, PC4, that mediates transcriptional activation of class II genes. Cell 78: 513-523.

Girard, F., Bello, B., Laemmli, U.K., and Gehring, W.J. 1998. In vivo analysis of scaffold-associated regions in Drosophila: A synthetic high-affinity SAR binding protein suppresses position effect variegation. EMBO J. 17: 2079-2085.

Glass, C.K. and Rosenfeld, M.G. 2000. The coregulator exchange in transcriptional functions of nuclear receptors. Genes \& Dev. 14: 121-141.

Goodrich, J.A., Hoey, T., Thut, C.J., Admon, A., and Tjian, R. 1993. Drosophila TAFII40 interacts with both a VP16 activation domain and the basal transcription factor TFIIB. Cell 75: 519-530.

Goodrich, J.A., Cutler, G., and Tjian, R. 1996. Contacts in context: Promoter specificity and macromolecular interactions in transcription. Cell 84: 825-830.

Grant, P.A., Duggan, L., Côté, J., Roberts, S.M., Brownell, J.E., Candau, R., Ohba, R., Owen-Hughes, T., C.D. Allis, F. Winston, et al. 1997. Yeast Gen5 functions in two multisubunit complexes to acetylate nucleosomal histones: Characterization of an Ada complex and the SAGA (Spt/Ada) complex. Genes \& Dev. 11: 1640-1650.

Grant, P.A., Schieltz, D., Pray-Grant, M.G., Steger, D.J., Reese, J.C., Yates, J.R., 3rd, and Workman, J.L. 1998. A subset of TAF(II)s are integral components of the SAGA complex required for nucleosome acetylation and transcriptional stimulation. Cell 94: 45-53.

Green, M.R. 2000. TBP-associated factors (TAFIIs): Multiple, selective transcriptional mediators in common complexes. Trends Biochem. Sci. 25: 59-63.

Grunstein, M. 1992. Histones as regulators of genes. Sci. Amer. 
267: 68-74B.

Gu, W., Malik, S., Ito, M., Yuan, C.X., Fondell, J.D., Zhang, X., Martinez, E., Qin, J., and Roeder, R.G. 1999. A novel human SRB/MED-containing cofactor complex, SMCC, involved in transcription regulation. Mol. Cell 3: 97-108.

Guarente, L. 1987. Regulatory proteins in yeast. Annu. Rev. Genet. 21: 425-452.

Hahm, K., Cobb, B.S., McCarty, A.S., Brown, K.E., Klug, C.A., Lee, R., Akashi, K., Weissman, I.L., Fisher, A.G., and Smale, S.T. 1998. Helios, a T cell-restricted Ikaros family member that quantitatively associates with Ikaros at centromeric heterochromatin. Genes \& Dev. 12: 782-796.

Hahn, S., Buratowski, S., Sharp, P.A., and Guarente, L. 1989. Isolation of the gene encoding the yeast TATA binding protein TFIID: A gene identical to the SPT15 suppressor of Ty element insertions. Cell 58: 1173-1181.

Hamamori, Y., Sartorelli, V. Ogryzko, V., Puri, P.L., Wu, H.Y., Wang, J.Y., Nakatani, Y., and Kedes, L. 1999. Regulation of histone acetyltransferases $\mathrm{p} 300$ and PCAF by the bHLH protein twist and adenoviral oncoprotein E1A. Cell 96: 405413.

Hamiche, A., Sandaltzopoulos, R., Gdula, D.A., and Wu, C. 1999. ATP-dependent histone octamer sliding mediated by the chromatin remodeling complex NURF. Cell 97: 833-842.

Hansen, S.K. and Tjian, R. 1995. TAFs and TFIIA mediate differential utilization of the tandem Adh promoters. Cell 82: $565-575$.

Hansen, S.K., Takada, S., Jacobson, R.H., Lis, J.T., and Tjian, R. 1997. Transcription properties of a cell type-specific TATAbinding protein, TRF. Cell 91: 71-83.

Hecht, A., Laroche, T., Strahl-Bolsinger, S., Gasser, S.M., and Grunstein, M. 1995. Histone H3 and H4 N-termini interact with SIR3 and SIR4 proteins: A molecular model for the formation of heterochromatin in yeast. Cell 80: 583-592

Henry, R.W., Mittal, V., Ma, R., Kobayashi, R., and Hernandez, N. 1998. Assembly of a functional, core promoter complex (SNAPc) shared by RNA polymerase II and III. Genes \& Dev. 12: 2664-2672.

Hittelman, A.B., Burakov, D., Iniguez-Lluhi, J.A., Freedman, L.P., and Garabedian, M.J. 1999. Differential regulation of glucocorticoid receptor transcriptional activation via AF-1 associated proteins. EMBO T. 18: 5380-5388.

Ho, C.K. and Shuman, S. 1999. Distinct roles for CTD Ser-2 and Ser-5 phosphorylation in the recruitment and allosteric activation of mammalian mRNA capping enzyme. Mol. Cell 3: 405-411

Hochschild, A., Irwin, N., and Ptashne, M. 1983. Repressor structure and the mechanism of positive control. Cell 32: 319-325.

Hoey, T., Weinzierl, R.O., Gill, G., Chen, J.L., Dynlacht, B.D., and Tjian, R. 1993. Molecular cloning and functional analysis of Drosophila TAF110 reveal properties expected of coactivators. Cell 72: 247-260.

Holmes, M.C. and Tjian, R. 2000. Promoter-selective properties of the TBP-related factor TRF1. Science 288: 867-870.

Holstege, F.C., Jennings, E.G., Wyrick, J.J., Lee, T.I., Hengartner, C.J., Green, M.R., Golub, T.R., Lander, E.S., and Young, R.A. 1998. Dissecting the regulatory circuitry of a eukaryotic genome. Cell 95: 717-728.

Horikoshi, M., Hai, T., Lin, Y.S., Green, M.R., and Roeder, R.G. 1988. Transcription factor ATF interacts with the TATA factor to facilitate establishment of a preinitiation complex. Cell 54: 1033-1042.

Horikoshi, M., Wang, C.K., Fujii, H., Cromlish, J.A., Weil, P.A., and Roeder, R.G. 1989. Cloning and structure of a yeast gene encoding a general transcription initiation factor TFIID that binds to the TATA box. Nature 341: 299-303.

Huang, S., Deerinck, T.J., Ellisman, M.H., and Spector, D.L. 1998. The perinucleolar compartment and transcription. J. Cell Biol. 143: 35-47.

Ikeda, K., Halle, J.P., Stelzer, G., Meisterernst, M., and Kawakami, K. 1998. Involvement of negative cofactor NC2 in active repression by zinc finger-homeodomain transcription factor AREB6. Mol. Cell. Biol. 18: 10-18.

Imai, S., Armstrong, C.M., Kaeberlein, M., and Guarente, L. 2000. Transcriptional silencing and longevity protein Sir2 is an NAD-dependent histone deacetylase. Nature 403: 795800.

Imbalzano, A.N., Kwon, H., Green, M.R., and Kingston, R.E. 1994. Facilitated binding of TATA-binding protein to nucleosomal DNA. Nature 370: 481-485.

Inostroza, J.A., Mermelstein, F.H., Ha, I., Lane, W.S., and Reinberg, D. 1992. Dr1, a TATA-binding protein-associated phosphoprotein and inhibitor of class II gene transcription. Cell 70: 477-489

Ito, M., Yuan, C.X., Malik, S., Gu, W., Fondell, J.D., Yamamura, S., Fu, Z.Y., Zhang, X., Qin, J., and Roeder, R.G. 1999. Identity between TRAP and SMCC complexes indicates novel pathways for the function of nuclear receptors and diverse mammalian activators. Mol. Cell 3: 361-370.

Ito, T., Levenstein, M.E., Fyodorov, D.V., Kutach, A.K., Kobayashi, R., and Kadonaga, J.T. 1999. ACF consists of two subunits, Acfl and ISWI, that function cooperatively in the ATP-dependent catalysis of chromatin assembly. Genes \& Dev. 13: 1529-1539.

Jacobson, R.H., Ladurner, A.G., King, D.S., and Tjian, R. 2000. Structure and function of a human TAF(II)250 double bromodomain module. Science 288: 1422-1425.

Jarriault, S., Brou, C., Logeat, F., Schroeter, E.H., Kopan, R., and Israel, A. 1995. Signalling downstream of activated mammalian Notch. Nature 377: 355-358.

Jenuwein, T., Forrester, W.C., Fernandez-Herrero, L.A., Laible, G., Dull, M., and Grosschedl, R. 1997. Extension of chromatin accessibility by nuclear matrix attachment regions. $\mathrm{Na}$ ture 385: 269-272.

Jimenez, G., Paroush, Z., and Ish-Horowicz, D. 1997. Groucho acts as a corepressor for a subset of negative regulators, including Hairy and Engrailed. Genes \& Dev. 11: 3072-3082.

Johnson, P.F., Landschulz, W.H., Graves, B.J., and McKnight, S.L. 1987. Identification of a rat liver nuclear protein that binds to the enhancer core element of three animal viruses. Genes \& Dev. 1: 133-146.

Kadonaga, J.T., Carner, K.R., Masiarz, F.R., and Tjian, R. 1987. Isolation of cDNA encoding transcription factor $\mathrm{Sp} 1$ and functional analysis of the DNA binding domain. Cell 51: 1079-1090.

Kadosh, D. and Struhl, K. 1997. Repression by Ume6 involves recruitment of a complex containing $\operatorname{Sin} 3$ corepressor and Rpd3 histone deacetylase to target promoters. Cell 89: 365371.

Kamei, Y., Xu, L., Heinzel, T., Torchia, J., Kurokawa, R., Gloss, B., Lin, S.-C., Heyman, R.A., Rose, D.W., Glass, C.K., et al. 1996. A CBP-integrator complex mediates transcriptional activation and AP-1 inhibition by nuclear receptors. Cell 85: 403-414.

Kim, J., Sif, S., Jones, B., Jackson, A., Koipally, J., Heller, E., Winandy, S., Viel, A. Sawyer, A., Ikeda, T. et al. 1999. Ikaros DNA-binding proteins direct formation of chromatin remodeling complexes in lymphocytes. Immunity 10: 345-355.

Kim, Y.-J., Bjorkland, S., Li, Y., Sayre, M.H., and Kornberg, R.D. 1994. A multiprotein mediator of transcriptional activation 
and its interaction with the C-terminal repeat domain of RNA Polymerase II. Cell 77: 599-608.

Kimura, H., Tao, Y., Roeder, R.G., and Cook, P.R. 1999. Quantitation of RNA polymerase II and its transcription factors in an HeLa cell: Little soluble holoenzyme but significant amounts of polymerases attached to the nuclear substructure. Mol. Cell. Biol. 19: 5383-5392.

Kingston, R.E. and Narlikar, G.J. 1999. ATP-dependent remodeling and acetylation as regulators of chromatin fluidity. Genes \& Dev. 13: 2339-2352.

Kirillov, A., Kistler, B., Mostoslavsky, R., Cedar, H., Wirth, T., and Bergman, Y. 1996. A role for nuclear NF-кB in B-cellspecific demethylation of the Igк locus. Nat. Genet. 13: 435441.

Koleske, A.J. and Young, R.A. 1994. An RNA Polymerase II holoenzyme responsive to activators. Nature 368: 466-469.

Komarnitsky, P.B., Michel, B., and Buratowski, S. 1999. TFIIDspecific yeast TAF40 is essential for the majority of RNA polymerase II-mediated transcription in vivo. Genes \& Dev. 13: $2484-2489$.

Kornberg, R. 1974. Chromatin structure: a repeating unit of histones and DNA. Science 184: 868-871.

Kowenz-Leutz, E. and Leutz, A. 1999. A C/EBP beta isoform recruits the SWI/SNF complex to activate myeloid genes. Mol. Cell 4: 735-743.

Krebs, J.E., Kuo, M.H., Allis, C.D., and Peterson, C.L. 1999. Cell cycle-regulated histone acetylation required for expression of the yeast HO gene. Genes \& Dev. 13: 1412-1421.

Kwok, R.P., Lundblad, J.R., Chrivia, J.C., Richards, J.P., Bachinger, H.P., Brennan, R.G., Roberts, S.G., Green, M.R., and Goodman, R.H. 1994. Nuclear protein CBP is a coactivator for the transcription factor CREB. Nature 370: 223-226.

Laherty, C.D., Yang, W.M., Sun, J.M., Davie, J.R., Seto, E., and Eisenman, R.N. 1997. Histone deacetylases associated with the $\mathrm{mSin} 3$ corepressor mediate mad transcriptional repression. Cell 89: 349-356.

Lai, E. and Darnell, J.E., Jr. 1991. Transcriptional control in hepatocytes: A window on development. Trends Biochem. Sci. 16: 427-430.

Lamond, A.I. and Earnshaw, W.C. 1998. Structure and function in the nucleus. Science 280: 547-553.

Längst, G., Bonte, E.J., Corona, D.F., and Becker, P.B. 1999. Nucleosome movement by CHRAC and ISWI without disruption or trans-displacement of the histone octamer. Cell 97: 843-852.

Laurent, B.C., Treitel, M.A., and Carlson, M. 1991. Functional interdependence of the yeast SNF2, SNF5, and SNF6 proteins in transcriptional activation. Proc. Natl. Acad. Sci. 88: $2687-2691$.

Lefstin, J.A. and Yamamoto, K.R. 1998. Allosteric effects of DNA on transcriptional regulators. Nature 392: 885-888.

Lenardo, M.J. and Baltimore, D. 1989. NF-kappa B: A pleiotropic mediator of inducible and tissue-specific gene control. Cell 58: 227-229.

LeRoy, G., Orphanides, G., Lane, W.S., and Reinberg, D. 1998. Requirement of RSF and FACT for transcription of chromatin templates in vitro. Science 282: 1900-1904.

Levine, M. and Hoey, T. 1988. Homeobox proteins as sequencespecific transcription factors. Cell 55: 537-540.

Lin, Y.S. and Green, M.R. 1991. Mechanism of action of an acidic transcriptional activator in vitro. Cell 64: 971-981.

Lis, J.T. and Wu, C. 1993. Protein traffic on the heat shock promoter: Parking, stalling, and trucking along. Cell 74: 1-4.

Liu, F. and Green, M.R. 1990. A specific member of the ATF transcription factor family can mediate transcription activation by the adenovirus E1a protein. Cell 61: 1217-1224.
Lo, W.S., Trievel, R.C., Rojas, J.R., Duggan, L., Hsu, J.Y., Allis, C.D., Marmonstein, R., and Berger, S.L. 2000. Phosphorylation of serine 10 in histone $\mathrm{H} 3$ is functionally linked in vitro and in vivo to GCN5-mediated acetylation at lysine 14. Mol. Cell 5: 917-926.

Lorch, Y., Cairns, B.R., Zhang, M., and Kornberg, R.D. 1998. Activated RSC-nucleosome complex and persistently altered form of the nucleosome. Cell 94: 29-34.

Lorch, Y., Lapointe, J.W., and Kornberg, R.D. 1987. Nucleosomes inhibit the initiation of transcription but allow chain elongation with the displacement of histones. Cell 49: 203210.

Luger, K., Mäder, A.W., Richmond, R.K., Sargent, D.F., and Richmond, T.J. 1997. Crystal structure of the nucleosome core particle at $2.8 \AA$ resolution. Nature 389: 251-260.

Lundblad, J.R., Kwok, R.P., Laurance, M.E., Harter, M.L., and Goodman, R.H. 1995. Adenoviral E1A-associated protein p300 as a functional homologue of the transcriptional coactivator CBP. Nature 374: 85-88.

Luo, Y. and Roeder, R.G. 1995. Cloning, functional characterization, and mechanism of action of the B-cell-specific transcriptional coactivator OCA-B. Mol. Cell. Biol. 15: 4115-4124.

Maldonado, E., Shiekhattar, R., Sheldon, M., Cho, H., Drapkin, R., Rickert, P., Lees, E., Anderson, C.W., Linn, S., and Reinberg, D. 1996. A human RNA Polymerase II complex associated with SRB and DNA-repair proteins. Nature 381: 8689.

Maldonado, E., Hampsey, M., and Reinberg, D. 1999. Repression: Targeting the heart of the matter. Cell 99: 455-458.

Malik, S., Guermah, M., and Roeder, R.G. 1998. A dynamic model for PC4 coactivator function in RNA polymerase II transcription. Proc. Nat1. Acad. Sci. 95: 2192-2197.

Malik, S., Gu, W., Wu, W., Qin, J., and Roeder, R.G. 2000. The USA-derived transcriptional coactivator PC2 is a submodule of TRAP/SMCC and acts synergistically with other PCs. Mol. Cell 5: 753-760.

Maniatis, T., Goodbourn, S., and Fischer, J.A. 1987. Regulation of inducible and tissue-specific gene expression. Science 236: $1237-1245$.

Martinez, E., Kundu, T.K., Fu, J., and Roeder, R.G. 1998. A human SPT3-TAFII31-GCN5-L acetylase complex distinct from transcription factor IID. I. Biol. Chem. 273: 23781-23785.

Matera, A.G. 1999. Nuclear bodies: Multifaceted subdomains of the interchromatin space. Trends Cell Biol. 9: 302-309.

Matsui, T., Segall, J., Weil, P.A., and Roeder, R.G. 1980. Multiple factors required for accurate initiation of transcription by purified RNA polymerase II. J. Biol. Chem. 255: 1199211996.

McClure, W.R. 1985. Mechanism and control of transcription initiation in prokaryotes. Annu. Rev. Biochem. 54: 171-204.

McCracken, S., Rosonina, E., Fong, N., Sikes, M., Beyer, A., O'Hare, K., Shuman, S., and Bentley, D. 1998. Role of RNA polymerase II carboxy-terminal domain in coordinating transcription with RNA processing. Cold Spring Harbor Symp. Quant. Biol. 63: 301-309.

McKenna, N.J., Nawaz, Z., Tsai, S.Y., Tsai, M.J., and O'Malley, B.W. 1998. Distinct steady-state nuclear receptor coregulator complexes exist in vivo. Proc. Natl. Acad. Sci. 95: 1169711702 .

McKnight, S. and Tjian, R. 1986. Transcriptional selectivity of viral genes in mammalian cells. Cell 46: 795-805.

McNally, J.G., Muller, W.G., Walker, D., Wolford, R., and Hager, G.L. 2000. The glucocorticoid receptor: Rapid exchange with regulatory sites in living cells. Science 
287: 1262-1265.

Mengus, G., May, M., Carré, L., Chambon, P., and Davidson, I. 1997. Human TAF(II) 135 potentiates transcriptional activation by the AF-2s of the retinoic acid, vitamin D3, and thyroid hormone receptors in mammalian cells. Genes \& Dev. 11: 1381-1395.

Mermelstein, F., Yeung, K., Cao, J., Inostroza, J.A., ErdjumentBromage, H., Eagelson, K., Landsman, D., Levitt, P. Tempst, P., and Reinberg, D. 1996. Requirement of a corepressor for Drl-mediated repression of transcription. Genes \& Dev. 10: 1033-1048.

Michel, B., Komarnitsky, P., and Buratowski, S. 1998. Histonelike TAFs are essential for transcription in vivo. Mol. Cell 2: 663-673.

Miesfeld, R., Rusconi, S., Godowski, P.J., Maler, B.A., Okret, S., Wikström, A.C., Gustafsson, J.A., and Yamamoto, K.R. 1986. Genetic complementation of a glucocorticoid receptor deficiency by expression of cloned receptor cDNA. Cell 46: 389-399.

Misteli, T., Cáceres, J.F., Clement, J.Q., Krainer, A.R., Wilkinson, M.F., and Spector, D.L. 1998. Serine phosphorylation of SR proteins is required for their recruitment to sites of transcription in vivo. J. Cell Biol. 143: 297-307.

Mitchell, P.J. and Tjian, R. 1989. Transcriptional regulation in mammalian cells by sequence-specific DNA binding proteins. Science 245: 371-378.

Mizzen, C.A., Yang, X.-J., Kokubo, T., Brownell, J.E., Bannister, A.J., Owen-Hughes, T., Workman, J., Wang, L., Berger, S.L., Kouzarides, et al. 1996. The TAFII250 subunit of TFIID has histone acetyltransferase activity. Cell 87: 1261-1270.

Munshi, N., Merika, M., Yie, J., Senger, K., Chen, G., and Thanos, D. 1998. Acetylation of HMG I/Y) by CBP turns off IFN beta expression by disrupting the enhanceosome. Mol. Cell 2: 457-467.

Myers, L.C., Gustafsson, C.M., Bushnell, D.A., Lui, M., Erdjument-Bromage, H., Tempst, P., and Kornberg, R.D. 1998. The Med proteins of yeast and their function through the RNA polymerase II carboxy-terminal domain. Genes \& Dev. 12: $45-54$.

Näär, A.M., Beaurang, P.A., Zhou, S., Abrahams, A., Solomon, W., and Tjian, R. 1999. Composite coactivator ARC mediates chromatin-directed transcriptional activation. Nature 398: 828-832.

Nagy, L., Kao, H.Y., Chakravarti, D., Lin, R.J., Hassig, C.A., Ayer, D.E., Schreiber, S.L., and Evans, R.M. 1997. Nuclear receptor repression mediated by a complex containing SMRT, mSin3A, and histone deacetylase. Cell 89: 373-380.

Nakajima, T., Uchida, C., Anderson, S.F., Lee, C.G., Hurwitz, J., Parvin, J.D., and Montminy, M. 1997. RNA helicase A mediates association of CBP with RNA polymerase II. Cell 90: $1107-1112$.

Namciu, S.J., Blochlinger, K.B., and Fournier, R.E. 1998. Human matrix attachment regions insulate transgene expression from chromosomal position effects in Drosophila melanogaster. Mol. Cell. Biol. 18: 2382-2391.

Nibu, Y., Zhang, H., and Levine, M. 1998. Interaction of shortrange repressors with Drosophila CtBP in the embryo. Science 280: 101-104.

Nissen, R.M. and Yamamoto, K.R. 2000. The glucocorticoid receptor inhibits NFкB by interfering with serine-2 phosphorylation of the RNA polymerase II carboxy-terminal domain. Genes \& Dev. 14: 2314-2329.

Ogryzko, V.V., Schlitz, R.L., Russanova, V., Howard, B.H., and Nakatani, Y. 1996. The transcriptional co-activators p300 and CBP are histone acetyltransferases. Cell 87: 953-959.

Ogryzko, V.V., Kotani, T., Zhang, X., Schlitz, R.L., Howard, T.,
Yang, X.J., Howard, B.H., J. Qin, and Nakatani, Y. 1998. Histone-like TAFs within the PCAF histone acetylase complex. Cell 94: 35-44.

Onate, S.A., Tsai, S.Y., Tsai, M.-J., and O'Malley, B.W. 1995. Sequence and characterization of a co-activator for the steroid hormone receptor superfamily. Science 270: 1354-1357.

Orphanides, G., Lagrange, T., and Reinberg, D. 1996. The general transcription factors of RNA polymerase II. Genes \& Dev. 10: 2657-2683.

Parvin, J.D. and Young, R.A. 1998. Regulatory targets in the RNA polymerase II holoenzyme. Curr. Opin. Genet. Dev. 8: $565-570$.

Pederson, T. 1998. Thinking about a nuclear matrix. I. Mol. Biol. 277: 147-159.

Pemberton, L.F., Rosenblum, J.S., and Blobel, G. 1999. Nuclear import of the TATA-binding protein: Mediation by the karyopherin Kap114p and a possible mechanism for intranuclear targeting. I. Cell Biol. 145: 1407-1417.

Peterson, C.L. and Herskowitz, I. 1992. Characterization of the yeast SWI1, SWI2, and SWI3 genes, which encode a global activator of transcription. Cell 68: 573-583.

Picard, D., Salser, S.J., and Yamamoto, K.R. 1988. A movable and regulable inactivation function within the steroid binding domain of the glucocorticoid receptor. Cell 54: 10731080.

Pombo, A., Cuello, P., Schul, W., Yoon, J.B., Roeder, R.G., Cook, P.R., and Murphy, S. 1998. Regional and temporal specialization in the nucleus: A transcriptionally-active nuclear domain rich in PTF, Oct1 and PIKA antigens associates with specific chromosomes early in the cell cycle. EMBO $J$. 17: $1768-1778$.

Pombo, A., Jackson, D.A., Hollinshead, M., Wang, Z., Roeder, R.G., and Cook, P.R. 1999. Regional specialization in human nuclei: Visualization of discrete sites of transcription by RNA polymerase III. EMBO J. 18: 2241-2253.

Ptashne, M. 1988. How eukaryotic transcriptional activators work. Nature 335: 683-689.

Ptashne, M. and Gann, A. 1997. Transcriptional activation by recruitment. Nature 386: 569-577.

Pugh, B.F. and Tjian, R. 1990. Mechanism of transcriptional activation by Sp1: Evidence for coactivators. Cell 61: 11871197.

- 1991. Transcription from a TATA-less promoter requires a multisubunit TFIID complex. Genes \& Dev. 5: 1935-1945.

Rabenstein, M.D., Zhou, S., Lis, J.T., and Tjian, R. 1999. TATA box-binding protein (TBP)-related factor 2 (TRF2), a third member of the TBP family. Proc. Nat1. Acad. Sci. 96: 47914796.

Rachez, C., Lemon, B.D., Suldan, Z., Bromleigh, V., Gamble, M., Näär, A.M., Erdjument-Bromage, H., Tempst, P., and Freedman, L.P. 1999. Ligand-dependent transcription activation by nuclear receptors requires the DRIP complex. Nature 398: 824-828.

Reines, D., Conaway, R.C., and Conaway, J.W. 1999. Mechanism and regulation of transcriptional elongation by RNA polymerase II. Curr. Opin. Cell Biol. 11: 342-346.

Reyes, J.C., Muchardt, C., and Yaniv, M. 1997. Components of the human SWI/SNF complex are enriched in active chromatin and are associated with the nuclear matrix. I. Cell Biol. 137: 263-274.

Roeder, R.G. and Rutter, W.J. 1969. Multiple forms of DNAdependent RNA polymerase in eukaryotic organisms. $\mathrm{Na}$ ture 224: 234-237.

Rougvie, A.E. and Lis, J.T. 1988. The RNA polymerase II molecule at the $5^{\prime}$ end of the uninduced hsp70 promoter is transcriptionally engaged. Cell 54: 795-804. 
Rundlett, S.E., Carmen, A.A., Kobayashi, R., Bavykin, S., Turner, B.M., and Grunstein, M. 1996. HDA1 and RPD3 are members of distinct yeast histone deacetylase complexes that regulate silencing and transcription. Proc. Natl. Acad. Sci. 93: 14503-14508.

Ryu, S., Zhou, S., Ladurner, A.G., and Tjian, R. 1999. The transcriptional cofactor complex CRSP is required for activity of the enhancer-binding protein Sp1. Nature 397: 446-450.

Sadoni, N., Langer, S., Fauth, C., Bernardi, G., Cremer, T., Turner, B.M., and Zink, D. 1999. Nuclear organization of mammalian genomes. Polar chromosome territories build up functionally distinct higher order compartments. J. Cell Biol. 146: 1211-1226.

Samuels, M., Fire, A., and Sharp, P.A. 1982. Separation and characterization of factors mediating accurate transcription by RNA polymerase II. J. Biol. Chem. 257: 14419-14427.

Scheer, U. and Hock, R. 1999. Structure and function of the nucleolus. Curr. Opin. Cell. Biol. 11: 385-390.

Schnitzler, G., Sif, S., and Kingston, R.E. 1998. Human Swi/SNF interconverts a nucleosome between its base state and a stable remodeled state. Cell 94: 17-27.

Schübeler, D., Francastel, C., Cimbora, D.M., Reik, A., Martin, D.I., and Groudine, M. 2000. Nuclear localization and histone acetylation: A pathway for chromatin opening and transcriptional activation of the human $\beta$-globin locus. Genes \& Dev. 14: 940-950.

Sif, S., Stukenberg, P.T., Kirschner, M.W., and Kingston, R.E. 1998. Mitotic inactivation of a human SWI/SNF chromatin remodeling complex. Genes \& Dev. 12: 2842-2851.

Smith, K.P., Moen, P.T., Wydner, K.L., Coleman, J.R., and Lawrence, J.B. 1999. Processing of endogenous pre-mRNAs in association with SC-35 domains is gene specific. J. Cell Biol. 144: 617-629.

Spencer, T.E., Jenster, G., Burcin, M.M., Allis, C.D., Zhou, J., Mizzen, C.A., McKenna, N.J., Onate, S.A., Tsai, S.Y., Tsai, M.-J., et al. 1997. Steroid receptor coactivator-1 is a histone acetyltransferase. Nature 389: 194-198.

Strahl, B.D. and Allis, C.D. 2000. The language of covalent histone modifications. Nature 403: 41-45.

Strubin, M., Newell, J.W., and Matthias, P. 1995. OBF-1, a novel B cell-specific coactivator that stimulates immunoglobulin promoter activity through association with octamer-binding proteins. Cell 80: 497-506.

Struhl, K. 1998. Histone acetylation and transcriptional regulatory mechanisms. Genes \& Dev. 12: 599-606.

Sun, X., Ma, D., Sheldon, M., Yeung, K., and Reinberg, D. 1994. Reconstitution of human TFIIA activity from recombinant polypeptides: A role in TFIID-mediated transcription. Genes \& Dev. 8: 2336-2348.

Sun, X., Zhang, Y., Cho, H., Rickert, P., Lees, E., Lane, W., and Reinberg, D. 1998. NAT, a human complex containing Srb polypeptides that functions as a negative regulator of activated transcription. Mol. Cell 2: 213-222.

Tacke, R. and Manley, J.L. 1999. Determinants of SR protein specificity. Curr. Opin. Cell Biol. 11: 358-362.

Takada, S., Lis, J.T., Zhou, S., and Tjian, R. 2000. A TRF1:BRF complex directs Drosophila RNA polymerase III transcription. Cell 101: 459-469.

Tamkun, J.W., Deuring, R., Scott, M.P., Kissinger, M., Pattatucci, A.M., Kaufman, T.C., and Kennison, J.A. 1992. Brahma: A regulator of Drosophila homeotic genes structurally related to the yeast transcriptional activator SNF2/ SWI2. Cell 68: 561-572.

Tanese, N., Pugh, B.F., and Tjian, R. 1991. Coactivators for a proline-rich activator purified from the multisubunit human TFIID complex. Genes \& Dev. 5: 2212-2224.
Taunton, J., Hassig, C.A., and Schreiber, S.L. 1996. A mammalian histone deacetylase related to the yeast transcriptional regulator Rpd3p. Science 272: 408-411.

Thompson, C.M., Koleske, A.J., Chao, D.M., and Young, R.A. 1993. A multisubunit complex associated with the RNA polymerase II CTD and TATA-binding protein in yeast. Cell 73: $1361-1375$.

Tirode, F., Busso, D., and Egly, J.M. 1999. Reconstitution of the transcription factor TFIIH: Assignment of functions for the three enzymatic subunits, XPB, XPD, and cdk7. Mol. Cell 3: 87-95.

Titov, A.A. and Blobel, G. 1999. The karyopherin Kap122p/ Pdr6p imports both subunits of the transcription factor IIA into the nucleus. J. Cell Biol. 147: 235-246.

Torchia, J., Rose, D.W., Inostroza, J., Kamei, Y., Westin, S., Glass, C.K., and Rosenfeld, M.G. 1997. The transcriptional co-activator $\mathrm{p} / \mathrm{CIP}$ binds CBP and mediates nuclear- receptor function. Nature 387: 677-684.

Triezenberg, S.J., Kingsbury, R.C., and McKnight, S.L. 1988. Functional dissection of VP16, the trans-activator of herpes simplex virus immediate early gene expression. Genes \& Dev. 2: 718-729.

Tsukiyama, T., Daniel, C., Tamkun, J., and Wu, C. 1995. ISWI, a member of the SWI2/SNF2 ATPase family, encodes the 140 $\mathrm{kDa}$ subunit of the nucleosome remodeling factor. Cell 83: 1021-1026.

Tsukiyama, T., Palmer, J., Landel, C.C., Shiloach, J., and Wu, C. 1999. Characterization of the imitation switch subfamily of ATP-dependent chromatin-remodeling factors in Saccharomyces cerevisiae. Genes \& Dev. 13: 686-697.

Tumbar, T., Sudlow, G., and Belmont, A.S. 1999. Large-scale chromatin unfolding and remodeling induced by VP16 acidic activation domain. J. Cell Biol. 145: 1341-1354.

Tyler, J.K. and Kadonaga, J.T. 1999. The "dark side" of chromatin remodeling: Repressive effects on transcription. Cell 99: 443-446.

Usheva, A. and Shenk, T. 1994. TATA-binding protein-independent initiation: YY1, TFIIB, and RNA polymerase II direct basal transcription on supercoiled template DNA. Cell 76: $1115-1121$.

Utley, R.T., Ikeda, K., Grant, P.A., Côté, J., Steger, D.J., Eberharter, A., John, S., and Workman, J.L. 1998. Transcriptional activators direct histone acetyltransferase complexes to nucleosomes. Nature 394: 498-502.

Verrijzer, C.P., Yokomori, K., Chen, J.L., and Tjian, R. 1994. Drosophila TAFII150: Similarity to yeast gene TSM-1 and specific binding to core promoter DNA. Science 264: 933941.

Verrijzer, C.P., Chen, J.L., Yokomori, K., and Tjian, R. 1995. Binding of TAFs to core elements directs promoter selectivity by RNA polymerase II. Cell 81: 1115-1125.

Verschure, P.J., van Der Kraan, I., Manders, E.M., and van Driel, R. 1999. Spatial relationship between transcription sites and chromosome territories. J. Cell Biol. 147: 13-24.

Voegel, J.J., Heine, M.J.S., Zechel, C., Chambon, P., and Gronemyer, H. 1996. TIF2, a 160kDa transcriptional mediator for the ligand-dependent activation function AF-2 of nuclear receptors. EMBO I. 15: 3667-3675.

Wang, W., Carey, M., and Gralla, J.D. 1992. Polymerase II promoter activation: Closed complex formation and ATPdriven start-site opening. Science 255: 450-453.

Wang, W., Xue, Y., Zhou, S., Kuo, A., Cairns, B.R., and Crabtree, G.R. 1996. Diversity and specialization of mammalian SWI/ SNF complexes. Genes \& Dev. 10: 2117-2130.

Wei, X., Somanathan, S., Samarabandu, J., and Berezney, R. 1999. Three-dimensional visualization of transcription sites 
and their association with splicing factor-rich nuclear speckles. J. Cell Biol. 146: 543-558.

Weinberger, C., Hollenberg, S.M., Ong, E.S., Harmon, J.M., Brower, S.T., Cidlowski, J., Thompson, E.B., Rosenfeld, M.G., and Evans, R.M. 1985. Identification of human glucocorticoid receptor complementary DNA clones by epitope selection. Science 228: 740-742.

Wieczorek, E., Brand, M., Jacq, X., and Tora, L. 1998. Function of TAF(II)-containing complex without TBP in transcription by RNA polymerase II. Nature 393: 187-191.

Wilson, A.C., LaMarco, K., Peterson, M.G., and Herr, W. 1993. The VP16 accessory protein HCF is a family of polypeptides processed from a large precursor protein. Cell 74: 115-125.

Xue, Y., Wong, J., Moreno, G.T., Young, M.K., Côté, J., and Wang, W. 1998. NURD, a novel complex with both ATPdependent chromatin-remodeling and histone deacetylase activities. Mol. Cell 2: 851-861.

Yang, X.J., Ogryzko, V.V., Nishikawa, J., Howard, B.H., and Nakatani, Y. 1996. A p300/CBP-associated factor that competes with the adenoviral oncoprotein E1A. Nature 382: 319-324.

Yokomori, K., Zeidler, M.P., Chen, J.L., Verrijzer, C.P., Mlodzik, M., and Tjian, R. 1994. Drosophila TFIIA directs cooperative DNA binding with TBP and mediates transcriptional activation.Genes \& Dev. 8: 2313-2233.

Yoshinaga, S.K., Peterson, C.L., Herskowitz, I., and Yamamoto, K.R. 1992. Roles of SWI1, SWI2 and SWI3 proteins for transcriptional enhancement by steroid receptors. Science 258: 1598-1604.

Yudkovsky, N., Logie, C., Hahn, S., and Peterson, C.L. 1999. Recruitment of the SWI/SNF chromatin remodeling complex by transcriptional activators. Genes \& Dev. 13: 23692374.

Zawel, L., Kumar, K.P., and Reinberg, D. 1995. Recycling of the general transcription factors during RNA polymerase II transcription. Genes \& Dev. 9: 1479-1490.

Zeng, C., Kim, E., Warren, S.L., and Berget, S.M. 1997. Dynamic relocation of transcription and splicing factors dependent upon transcriptional activity. EMBO J. 16: 1401-1412.

Zhang, Y., Iratni, R., Erdjument-Bromage, H., Tempst, P., and Reinberg, D. 1997. Histone deacetylases and SAP18, a novel polypeptide, are components of a human $\operatorname{Sin} 3$ complex. Cell 89: 357-364.

Zhang, Y., LeRoy, G., Seelig, H.P., Lane, W.S., and Reinberg, D. 1998. The dermatomyositis-specific autoantigen $\mathrm{Mi} 2$ is a component of a complex containing histone deacetylase and nucleosome remodeling activities. Cell 95: 279-289. 


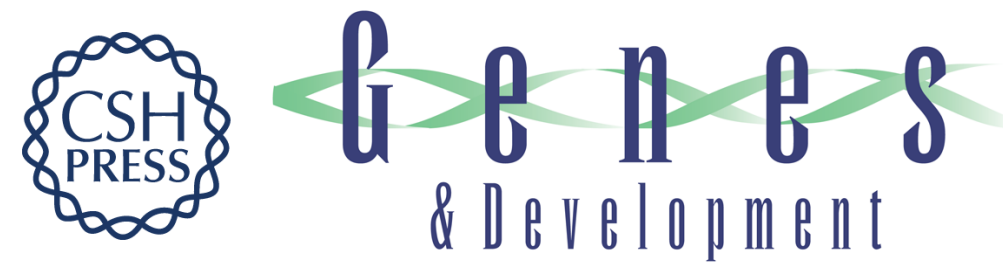

\section{Orchestrated response: a symphony of transcription factors for gene control}

Bryan Lemon and Robert Tjian

Genes Dev. 2000, 14:

Access the most recent version at doi:10.1101/gad.831000

References This article cites 223 articles, 86 of which can be accessed free at: http://genesdev.cshlp.org/content/14/20/2551.full.html\#ref-list-1

License

Email Alerting Receive free email alerts when new articles cite this article - sign up in the box at the top Service right corner of the article or click here.

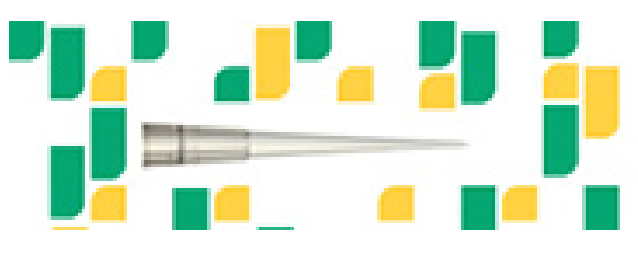

Focused on your science. 